\title{
Liquid crystal supermolecules stabilizing an optically isotropic phase with frustrated molecular organization
}

\begin{abstract}
Atsushi Yoshizawa
Cubic and blue phases have attracted a significant amount of attention because of their unusual phase structures with optical isotropy and because of their application to ion transfer in the cubic phase and to electrooptical switching in the blue phase. However, the driving forces for the frustrated liquid-crystalline phases differ from those for a conventional liquid-crystalline phase composed of rod-like molecules. We show that preprogrammed liquid-crystalline supermolecules can stabilize frustrated molecular organization in optically isotropic phases. Competition between steric effects caused by a taper-shaped oligomeric structure and segregation effects attributable to hydrocarbon/fluorocarbon amphiphilicity produces fluctuation of the layer structure, inducing the lamellar-to-cubic phase transition. Cooperation between inherent molecular chirality and the chiralityinduced twist conformations of the mesogenic units stabilizes double-twist structures in blue phases. Furthermore, we demonstrate high-transmittance, sub-millisecond responses and hysteresis-free switching in a room temperature amorphous blue phase stabilized by a liquid crystal supermolecule.
\end{abstract}

Polymer Journal (2012) 44, 490-502; doi:10.1038/pj.2012.55; published online 9 May 2012

Keywords: blue phase; chirality; cubic phase; display; liquid crystal; molecular assembly; supermolecule

\section{INTRODUCTION}

Supermolecular assemblies with well-defined morphologies are fundamental components in the structural formation in biological systems and in the production of novel functional materials. For those reasons, an investigation of the driving forces underlying this self-assembly process is important. ${ }^{1-14}$ The primary factor in the thermotropic liquid-crystalline phases is the gross molecular shape of compounds. ${ }^{1,2}$ Well-designed intermolecular interactions, that is, metal-containing systems, ${ }^{3,4}$ charge-transfer systems ${ }^{5}$ and hydrogenbonded systems, ${ }^{6}$ have been investigated. Furthermore, molecular topology ${ }^{7}$ and microsegregation ${ }^{8}$ have been recognized as the origins for producing novel self-organizing systems. These approaches have produced functional liquid crystals as designed self-assemblies. ${ }^{9-11}$ Supramolecular assemblies comprising supermolecules, ${ }^{12}$ that is, dimeric and oligomeric liquid crystals, ${ }^{13-15}$ and dendrimers ${ }^{16}$ have been investigated extensively. Liquid crystal oligomers consist of molecules containing two or more mesogenic units interconnected via flexible spacers. Dimeric liquid crystals are attractive because they exhibit different properties from those of conventional lowmolecular-mass liquid crystals and serve as models for main chain liquid crystal polymers. For instance, the transition properties of dimeric liquid crystals are known to depend on the length and parity of the flexible spacer. Pronounced odd-even effects were observed for transition properties of linear liquid crystal oligomers when the spacer length was varied. The transition behavior is interpreted in terms of how the spacers control the average molecular shape. Figure 1 depicts some examples of liquid crystal oligomers and dendrimers. Nonlinear molecular shapes in which one mesogenic unit is connected at a lateral site produce $\lambda$-shaped ${ }^{17,18}$ and T-shaped ${ }^{19-21}$ liquid crystals. The descriptions of T-, $\mathrm{U}$ - and $\lambda$-shaped molecules generally refer to their schematic representations, but in a liquid-crystalline phase, the molecules tend to adopt extended conformations in which the mesogenic units try to align themselves to the director. Different molecular arrangements of mesogenic units may lead to a rich polymorphism. Monolayer organization vs the intercalation of the dimesogens can engender commensurate and/or incommensurate structuring. ${ }^{22}$ Coupling between chirality and oligomeric structures can produce novel phenomena. Interesting odd-even effects were observed for chiral properties of dimeric liquid crystals. ${ }^{23,24}$ Supermolecules comprising preorganized mesogenic units have been designed because they can form secondary and tertiary structures with unique physical properties. Particularly, the molecular design for frustrated liquid-crystalline phases with a hierarchical structure has become an attractive field of materials science. ${ }^{25}$ Among frustrated phases, we specifically focus on optically isotropic phases, that is, cubic and blue phases, in this review.

Liquid crystals are characterized by birefringence because they have optical anisotropy. However, some liquid crystals, that is, cubic and blue phases, exhibit optical isotropy. Cubic liquid-crystalline phases, which represent three-dimensional-ordered supramolecular 
arrangements, such as interpenetrating networks and spheroids, have recently attracted much attention. ${ }^{26-28}$ Cubic mesophases are common in lyotropic systems, such as surfactant-solvent systems. The mesophase morphologies of these amphiphilic systems are governed mainly by the volume fraction of the two incompatible segments combined in such molecules. Upon increasing the volume fraction of one component, the phase sequence of lamellar (smectic, SmA), bicontinuous cubic $\left(\mathrm{Cub}_{\mathrm{v}}\right)$, hexagonal columnar $\left(\mathrm{Col}_{\mathrm{h}}\right)$, and micellar cubic $\left(\mathrm{Cub}_{\mathrm{I}}\right)$ is typical for the morphologies of the mesophases of these systems (see Figure 2). The value of the interface

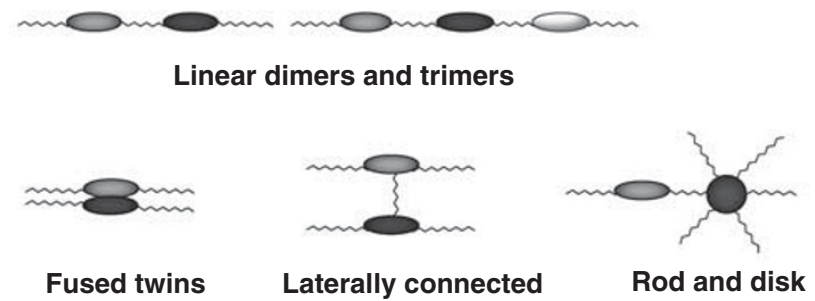

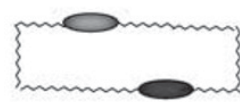

Cyclic dimers and oligomers

Lateral trimers

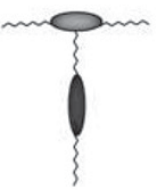

T shape

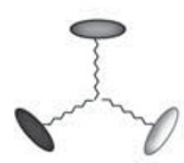

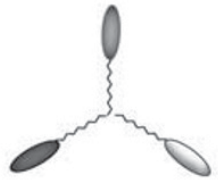

Terminal trimers

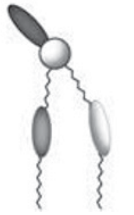

$\lambda$ shape

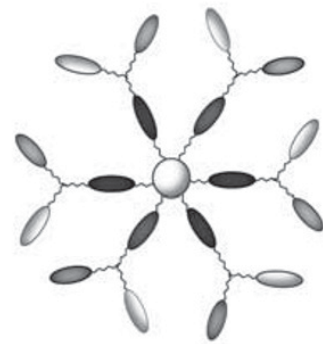

Dendrimers curvature between hydrophilic regions and lipophilic regions is recognized as the key factor determining the mesophase morphology of these systems..$^{29,30}$ Cubic structures can also be found in amphiphilic block copolymers ${ }^{31}$ and polyelectrolytes. ${ }^{32}$ In contrast to lyotropic cubic systems, some thermotropic compounds with a cubic phase are also known. They have been found for nitrosubstituted and cyano-substituted biphenyl carboxylic acids, ${ }^{33-35}$ dibenzoylhydrazides, ${ }^{36}$ polycatenar compounds, ${ }^{37-39}$ metal complexes, ${ }^{40,41}$ amphiphilic polyhydroxy compounds ${ }^{42,43}$ and carbohydrate derivatives. $^{44}$ In most cases, bicontinuous cubic mesophases have been found for these cubic phases. In the case of polyhydroxy derivatives, as depicted in Figure 3, the same sequence of

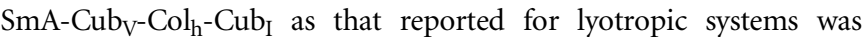
obtained. ${ }^{42,43}$ Mesophase morphologies are dominated by the interface curvature between hydrophilic regions and lipophilic regions. ${ }^{8}$ Furthermore, some chiral cubic phases have been reported. ${ }^{45-47}$ Chirality has an important role in the appearance of the cubic phase. Lyotropic cubic systems are known to show interesting biological activities. The inverse cubic phase derived from the self-assembly of surfactants in water offers a unique threedimensional platform for protein binding. Cubic phase particles (cubosomes) have been investigated extensively. ${ }^{48,49}$ However, thermotropic cubic systems have high viscosity. Therefore, few reports describe their application to electrooptical devices. ${ }^{50}$ Recently, unique and interesting properties have been observed in some cubic systems. ${ }^{51-53}$ Sagara and Kato ${ }^{51}$ reported a new type of cubic liquid crystal that exhibits three luminescent colors, which can be switched by mechanical and thermal stimuli. Kato et al. ${ }^{52}$ reported that 3D-interconnected ionic channels derived from the polymerization of bicontinuous cubic liquid crystals function as efficient ion-conductive pathways.

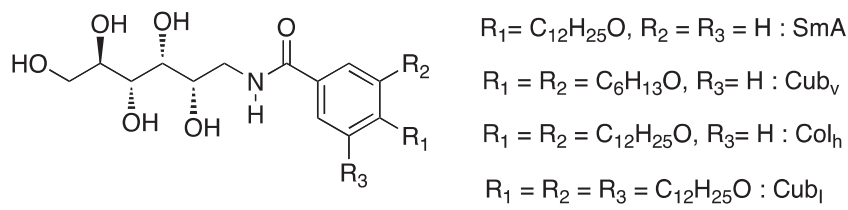

Figure 3 The dependence of mesophase formation of the polyhydroxy amphiphiles on the molecular structure. ${ }^{8,43}$

Figure 1 Types of liquid-crystalline supermolecules. ${ }^{1,12}$

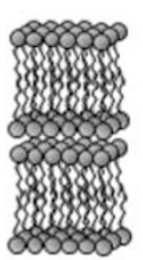

SmA

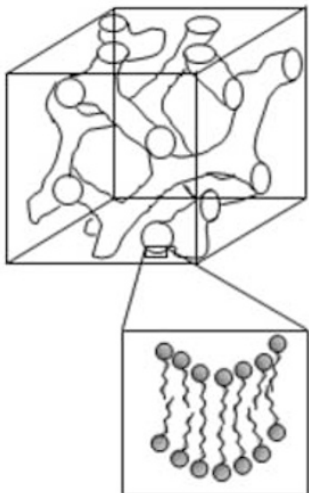

Cub $_{v}$
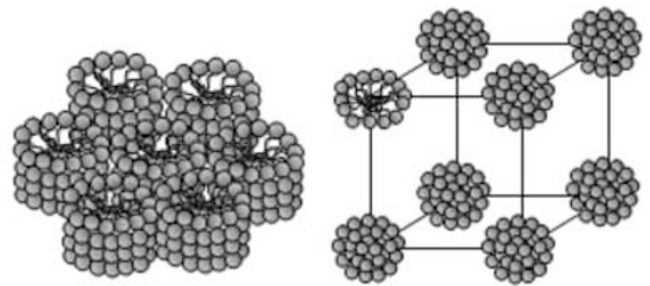

$\mathrm{Col}_{\mathrm{h}}$
Cub $_{1}$

Figure 2 Schematic sketches for morphologies of lamellar (smectic, SmA), bicontinuous cubic (Cubb), hexagonal columnar (Col ${ }_{h}$ ) and micellar cubic (Cubl) phases. A full color version of this figure is available at Polymer Journal online. 
Blue phases are of particular interest because they have a fluid lattice with a structure stabilized by lattice defects. Believed to consist of double-twist cylinders, they are classified into three categories, depending on the cylinders' packing structure: blue phase I (BPI), blue phase II (BPII) and blue phase III (BPIII). ${ }^{54}$ Figure 4 presents schematic representations of the blue phase structures. The packing structure of BPI is a body-centered cubic structure; BPII has a simple cubic structure. ${ }^{55,56}$ BPI and BPII are highly ordered, their disclination networks form a regular cubic lattice, and their physics are well understood. By contrast, the structure of BPIII is unsolved. Theorists have proposed that BPIII consists of double-twisted cylinders with arbitrary orientation..$^{5,57,58}$ Recently, Henrich et al. ${ }^{59}$ proposed that BPIII is an amorphous network of disclination lines that is thermodynamically and kinetically stabilized over crystalline blue phases at intermediate chiralities. Figure 5a shows an optical texture of cubic BPI under crossed polarizers. A platelet texture with fine stripes is characteristic of BPI. Figure $5 b$ presents a fog texture of amorphous BPIII. BPI and BPII often appear as a display of many colorful platelets, whereas BPIII appears as a foggy bluish substance. BPI and BPII are cubic with lattice parameters on the order of visible wavelengths. Therefore, there may be several selective reflection wavelengths corresponding to various crystal planes. If the cubic blue phases contain many domains that are oriented differently for each domain, their textures show a mosaic of color. ${ }^{54,60}$ Usually, blue phases are found in an extremely narrow temperature range $(\mathrm{ca} .1 \mathrm{~K})$ between the isotropic liquid (Iso) and the chiral nematic $\left(\mathrm{N}^{*}\right)$ phase of sufficiently short pitch. Electric field effects in blue phases have been investigated. ${ }^{54}$ An applied field can produce three distinct transformations: a local reorientation of the molecules, distortion of the lattice (electrostriction) and phase transition to lower symmetry phases. ${ }^{61-67}$ Blue phases are potentially useful for application as fast light modulators or tunable photonic crystals, but their narrow temperature range presents a critical problem. Therefore, stabilizing the blue phases has attracted much attention. The most successful approach is polymer stabilization, as reported by Kikuchi et al. ${ }^{68,69}$ Specific polymer networks can stabilize the lattice defects of BPI. ${ }^{70}$ The temperature range of the polymer-stabilized BPI is extended to more than $60 \mathrm{~K}$. Fast electrooptical switching with a response time of $10^{-4} \mathrm{~s}$ was demonstrated in the polymer-stabilized BPI. Blue phases have several advantages: (1) they require no alignment layer; (2) their response time is in the sub-millisecond range, which enables color-sequential displays; and (3) their dark state is optically isotropic so that its viewing angle is wide and symmetric without optical-compensating filters. ${ }^{71}$ A BP liquid crystal display (LCD) mode using polymer-stabilized BPI was developed in earlier studies. ${ }^{72-76}$ With respect to a low-molecular-mass system, Coles and Pivnenko ${ }^{77}$ reported that eutectic mixtures of three homologs of a symmetric dimer doped with a small quantity of a high-twisting chiral additive show BPI with a very wide temperature range. Other approaches, for example, chiral molecules, ${ }^{78}$ polymer network surfaces, ${ }^{79}$ nanoparticle stabilization, ${ }^{80,81}$ hydrogen-bonded molecules ${ }^{82}$ and achiral bent-core molecules, ${ }^{83-87}$ are also successful at broadening the blue phase range. In particular, doping achiral bent-core molecules shows marked enhancement of the BPI range. The effect is interpreted as a reduction in the free energy cost for defects, stabilizing the double-twist cylinders. The stability of BPI is enhanced when $K_{33}$ is smaller than $K_{11}{ }^{87}$

\section{LIQUID-CRYSTALLINE SUPERMOLECULES STABILIZING A CUBIC PHASE}

\section{Amphiphilic-tapered compounds}

Microsegregation produced by amphiphilicity is an important concept for producing higher-ordered systems. Amphiphilicity is produced by incompatible units within a molecule. We designed tapered

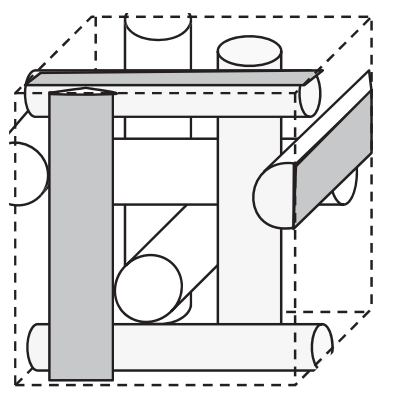

BPI

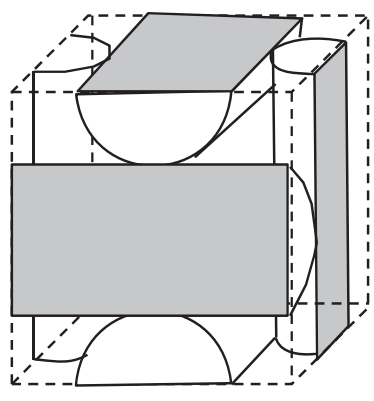

BPII

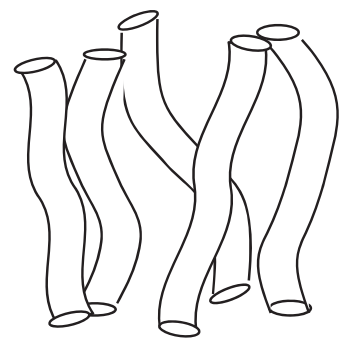

BPIII

Figure 4 Schematic representations of the blue phase structures.
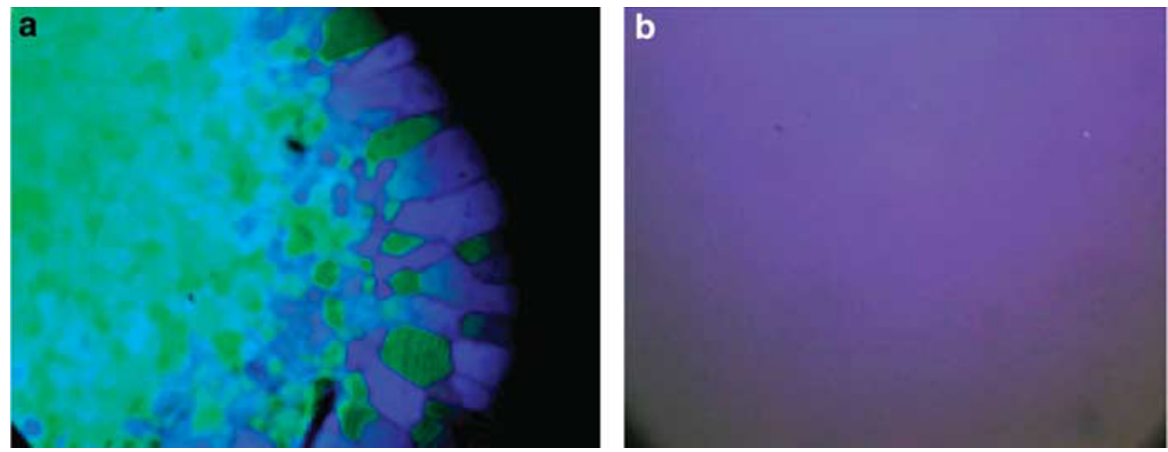

Figure 5 Optical textures of (a) BPI and (b) BPIII under crossed polarizers. 
compounds possessing hydrocarbon/fluorocarbon incompatibility and shape incompatibility ${ }^{88}$ Figure 6 shows the molecular structures and the phase transition temperatures of the amphiphilic liquidcrystalline compounds 1-3 composed of cyanobiphenyl mesogenic moieties and a semiperfluorinated alkyl chain.

The compounds showed an unusual phase sequence of lamellarcolumnar-bicontinuous cubic phases when the number of cyanobiphenyl moieties was increased. Figure 7 presents an optical texture of the SmA-Cub phase transition for compound 3. In the amphiphilic polyhydroxy derivatives, the phase sequence of $\mathrm{SmA}-\mathrm{Cub}_{\mathrm{V}}-\mathrm{Col}_{\mathrm{h}}-\mathrm{Cub}_{\mathrm{I}}$ was obtained by increasing the number and length of the aliphatic chains to make them similar to surfactants of the lyotropic systems. ${ }^{42,43}$ Moreover, the tetracatenar compounds showed the

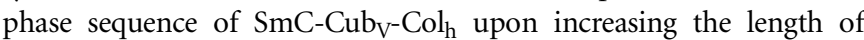
the terminal aliphatic chains. ${ }^{39,41}$ By contrast, the amphiphilic liquidcrystalline compounds 1-3 showed a different phase sequence of SmC-Col-Cub upon increasing the cyanobiphenyl mesogenic moieties; the sequence of Col-Cub is opposite that of the ordinary

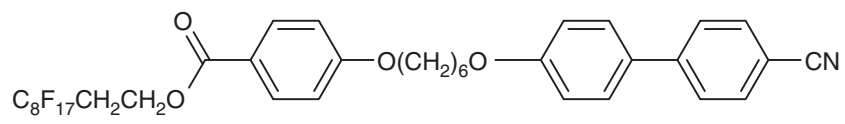

1: Cry $110^{\circ} \mathrm{C} \mathrm{SmC} 140^{\circ} \mathrm{C}$ Iso

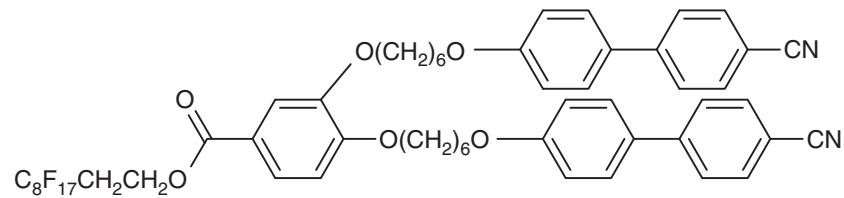

2: Cry $62{ }^{\circ} \mathrm{C} \mathrm{Col} 134{ }^{\circ} \mathrm{C} \mathrm{SmA} 171^{\circ} \mathrm{C}$ Iso

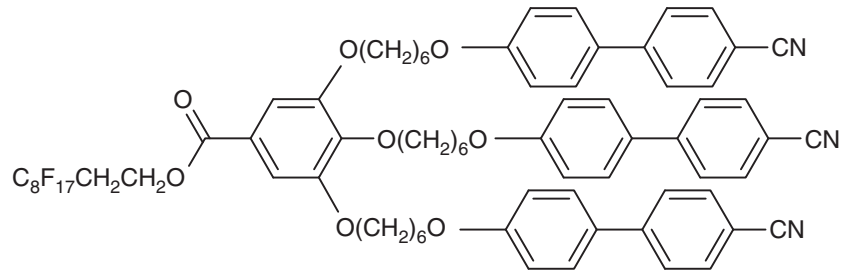

3: Cry $83^{\circ} \mathrm{C}$ Cub $141^{\circ} \mathrm{C} \mathrm{SmA} 155^{\circ} \mathrm{C}$ Iso

Figure 6 Molecular structures and phase transition temperatures of amphiphilic liquid-crystalline oligomers $\mathbf{1}-\mathbf{3} .^{88}$

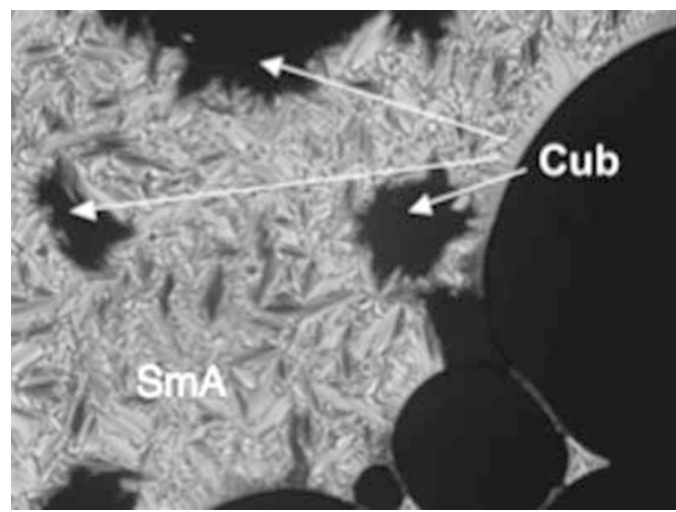

Figure 7 Optical texture of the SmA-Cub phase transition for compound 3. ${ }^{88} \mathrm{~A}$ full color version of this figure is available at Polymer Journal online. sequence. Based on the X-ray analysis, ${ }^{88}$ the Col phase of compound 2 has a rectangular 2D lattice, and the Cub phase of compound 3 belongs to a space group $I a 3 d$, which represents a bicontinuous cubic phase constructed from two interpenetrating networks of branched cylinders (Figure 8). ${ }^{26}$ The SmA-to-Col transition of compound 2 is explained by (1) the interfacial curvature between the region of the fluorinated alkyl chains and that of the cyanobiphenyl cores and aliphatic alkyl spacers and (2) layer deformation induced by the $\lambda$ shaped molecule. To understand the appearance of the cubic phase of compound 3, we prepared compounds 4 and 5 (Figure 9). Compound 4, which was formed by replacing the cyano unit with hydrogen, showed a phase sequence of Iso-Col. ${ }^{89}$ Compound 5, which was created by replacing the fluorocarbon with hydrocarbon, showed a phase sequence of Iso-nematic (N). ${ }^{90}$ XRD measurements of compound 3 suggest that the SmA phase has a fluctuating layer structure. The competition of two different molecular packings, that is, (a) a segregation effect attributable to incompatibility between a semiperfluorinated moiety and cyanobiphenyl mesogens and (b) a

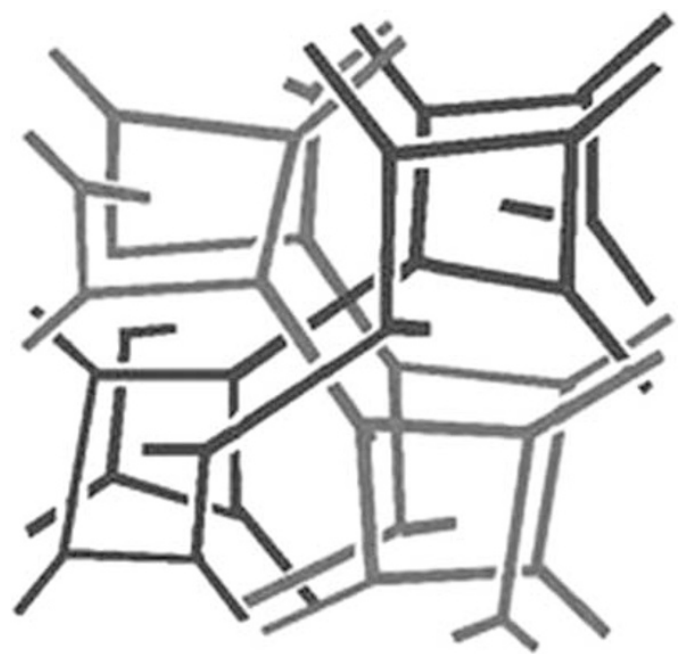

Figure 8 Bicontinuous cubic phase with the pace group la3d. ${ }^{26} \mathrm{~A}$ full color version of this figure is available at Polymer Journal online.

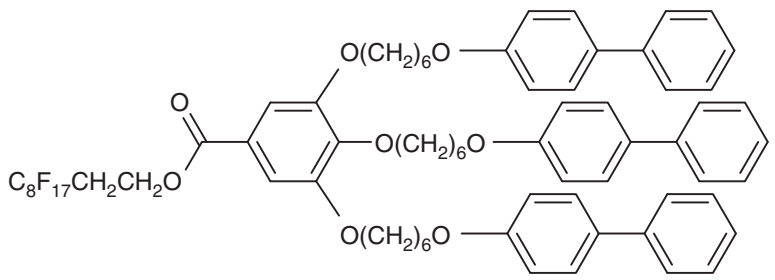

4: Cry $104.7^{\circ} \mathrm{C}\left[\mathrm{Col} 87.9^{\circ} \mathrm{C}\right]$ Iso

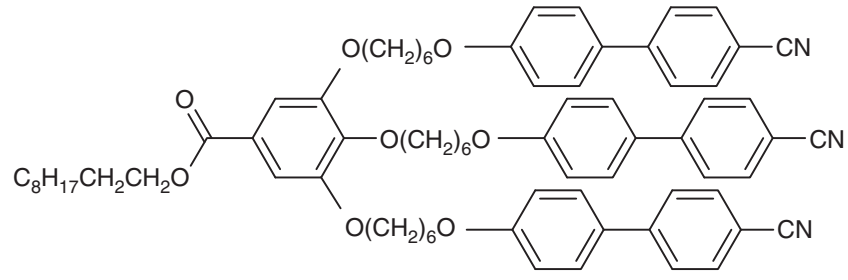

5: Cry $106.5^{\circ} \mathrm{C}$ [glass $9.4^{\circ} \mathrm{C} \mathrm{N} 101.7^{\circ} \mathrm{C}$ ] Iso

Figure 9 Molecular structures and phase transition temperatures of compounds 4 and $\mathbf{5}$. 
steric effect attributable to the pronounced tapered shape of compound 3, might give rise to that fluctuation. An undulatory deformation mode for a nonequilibrium lamellar structure is known to exist as the unstable transient state between the lamellar and the Cub (Gyroid with a space group Ia3d) phases in some diblock copolymers. ${ }^{91}$ Fluctuations of the lamellar structure before a lamellarto-gyroid transition in a nonionic surfactant system were observed. ${ }^{92}$ An interesting explanation for the fluctuations has been proposed: (1) amplitude modulation fluctuations appear in lamellae, (2) modulation fluctuations increase their amplitude as the temperature approaches the transition and (3) they develop into a perforation fluctuation layer as an equilibrium structure. ${ }^{92}$ The fluctuated lamellar structure in the SmA phase of compound 3 is most likely stabilized by antiparallel dipole-dipole interactions between the cyanobiphenyl groups in adjacent layers, which can produce the $\mathrm{Cub}_{\mathrm{V}}$ phase (Figure 10). ${ }^{88,93}$ This mechanism of the formation of the
$\mathrm{Cub}_{\mathrm{V}}$ phase is a novel one in low-molecular-mass thermotropic liquid-crystalline systems.

Next, we designed an amphiphilic liquid crystal hexamer (6) possessing six cyanobiphenyl moieties and a semiperfluorinated alkyl chain. ${ }^{94}$ Compound 6 has a dimeric structure in which two tapered moieties of compound $\mathbf{6}$ are connected via a semiperfluorinated alkyl spacer. Therefore, molecular packing by the steric effect attributable to a pronounced tapering is regarded as inhibited. Compound 6 exhibited monotropic $\mathrm{N}$ and two SmA phases, designated as SmA and $\mathrm{SmA}^{\prime}$, but not the $\mathrm{Cub}_{\mathrm{V}}$ phase. The layer spacings in the $\mathrm{SmA}$ and $\mathrm{SmA}^{\prime}$ phases of compound 6 were found to be $44.3 \AA$ and $17.9 \AA$, respectively. The molecular lengths were estimated to be approximately $65 \AA$ for elongated molecular conformation, $51 \AA$ for the bent structure and $26 \AA$ for the folded structure. Figure 11 shows a model for the lamellar-to-lamellar phase transition of compound $\mathbf{6}$. In the higher-temperature SmA phase, the segregation effect is

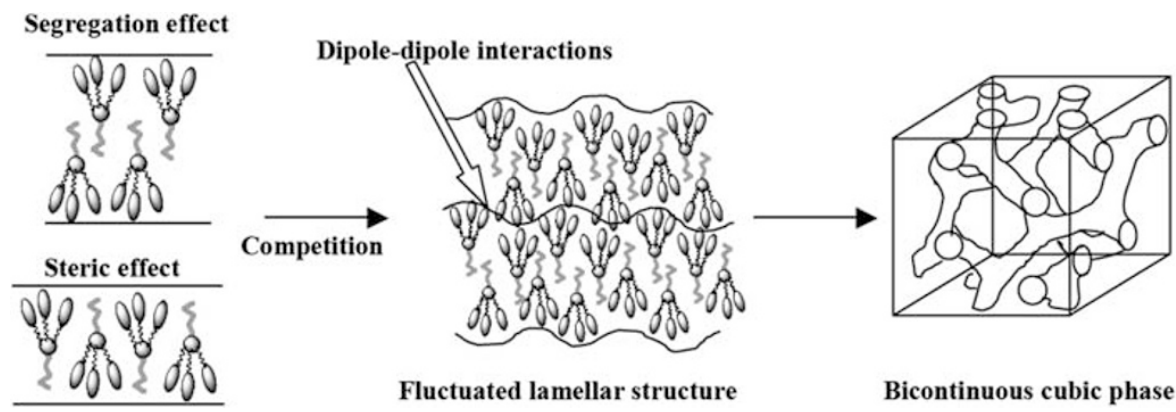

Figure 10 Schematic illustration of the driving forces for the fluctuated SmA phase and the bicontinuous cubic phase of compound $3{ }^{88,93}$ (Reprinted with permission from Takeuchi et al. ${ }^{93}$ Copyright 2010, Taylor \& Francis). A full color version of this figure is available at Polymer Journal online.

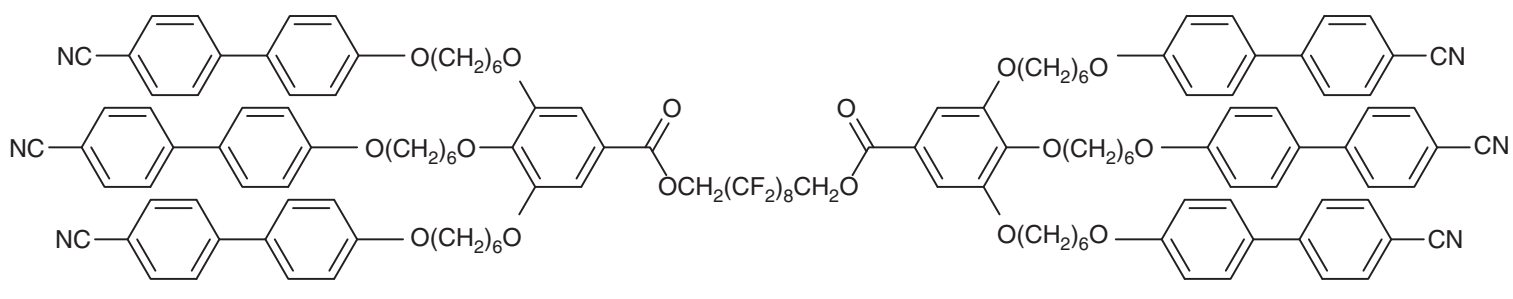

6: $\mathrm{Cr} 122.0^{\circ} \mathrm{C}\left[\mathrm{SmA}^{\prime} 46.8^{\circ} \mathrm{C} \mathrm{SmA} 101.8^{\circ} \mathrm{C} \mathrm{N} 121.4^{\circ} \mathrm{C}\right]$ Iso

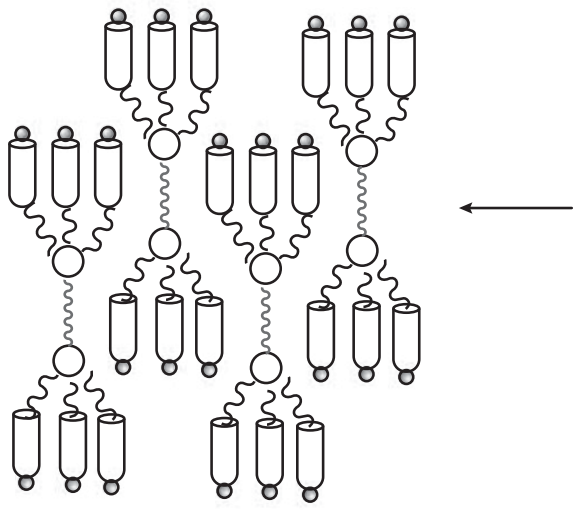

SmA

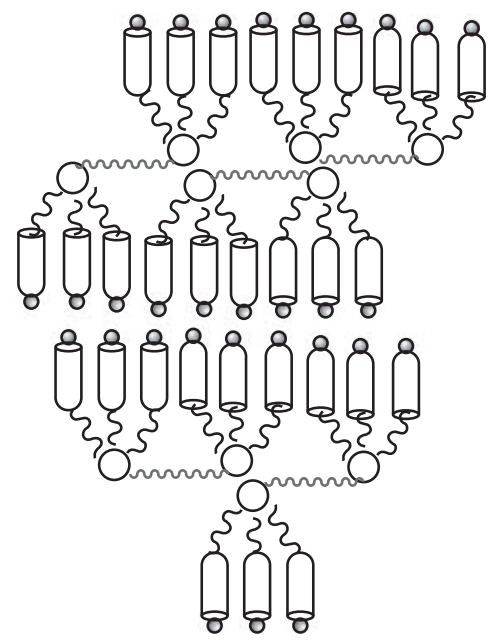

SmA

Figure 11 Molecular structure and phase transition temperatures of hexamer 6 and a model for the lamellar-to-lamellar phase transition. ${ }^{94} \mathrm{~A}$ full color version of this figure is available at Polymer Journal online. 
dominant. Therefore, the molecules are thought to adopt bent and/or folded conformations. Moreover, they are organized into a layer structure in which the cyanobiphenyl mesogenic units and the semiperfluorinated unit are segregated into different sublayers. In the lower-temperature $\mathrm{SmA}^{\prime}$ phase, the steric effect is dominant; the molecules have an elongated conformation and form an intercalated layer structure.

\section{LIQUID-CRYSTALLINE SUPERMOLECULES STABILIZING BLUE PHASES}

Binaphthyl derivatives

The appearance of blue phases results from the competition between the chiral twisting force and the desire for molecules to fill space uniformly. Theoretical work suggests that biaxiality has an important role in the blue phases. ${ }^{95}$ However, the biaxiality in most chiral rod-like nematic liquid crystals is slight. For that reason, the double-twist structure cannot exist over a wide temperature range in conventional liquid crystals.

We designed coupling between molecular biaxiality and chirality. The first material is a binaphthyl derivative, 7-n (Figure 12). ${ }^{96}$ The binaphthyl derivatives with odd-numbered spacers exhibited a blue phase with a relatively wide temperature range between the Iso and SmA phases, whereas those with even-numbered spacers showed an $\mathrm{N}^{*}$ phase, as shown in Table 1 .

Induced pitches in a host nematic liquid crystal doped with each odd dimer were longer than those with each even dimer, indicating that the twisting power of the odd dimers is less than that of the even dimers. Therefore, not only the twisting power of the chiral compound but also the molecular shape affects the blue phase stability. Actually, MM2 models of compounds 7-6 and 7-7 show that the configuration of the mesogenic groups of the odd dimer is more twisted than that of the even dimer (Figure 13). It is noteworthy that the molecular shape obtained from the MM2 calculations does not reflect a real structure of the chiral dimer in the liquid-crystalline phase. The crystal structure of the chiral dimer provides some insight into the molecular shape. However, we have not obtained the crystal structure yet. We investigated the chirality transfer from a binaphthyl

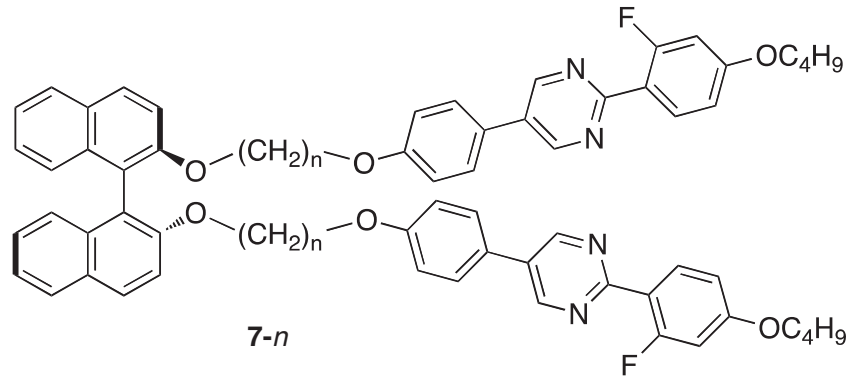

Figure 12 Molecular structure of binaphthyl derivative 7-n.

Table 1 Transition temperatures $\left({ }^{\circ} \mathrm{C}\right)$ on cooling for compounds $7-n^{96}$

\begin{tabular}{llllllll}
\hline $\mathrm{n}$ & SmA & & $N^{*}$ & & $B P$ & & । \\
\hline 6 & $\bullet$ & 63 & $\bullet$ & 113 & & & $\bullet$ \\
7 & $\bullet$ & 94 & & & $\bullet$ & 103 & $\bullet$ \\
8 & $\bullet$ & 105 & $\bullet$ & 124 & & & $\bullet$ \\
9 & $\bullet$ & 116 & & & $\bullet$ & 120 & $\bullet$ \\
10 & $\bullet$ & 108 & $\bullet$ & 122 & & & $\bullet$ \\
11 & $\bullet$ & 127 & & & $\bullet$ & 127 & $\bullet$ \\
12 & $\bullet$ & 135 & & & & & $\bullet$ \\
\hline
\end{tabular}

dimer possessing two biphenyl moieties to a host nematic liquid crystal. The results showed that the binaphthyl dimer has two origins for the twisting power: the asymmetric axis of the binaphthyl unit and the twist conformation of the two biphenyl moieties. ${ }^{97}$ The appearance of the BP of compound 7- $\boldsymbol{n}$ possessing odd-numbered spacers is explainable in that the two origins for the twisting power are thought to produce a biaxial helix (Figure 14), which can stabilize the BP.

To obtain a chiral compound possessing a wider temperature range for the blue phase, we prepared a binaphthyl derivative (8- $\boldsymbol{n})$ possessing two 2,3-difluoro-1,4-diphenylbenzene units in each 2-position (Figure 15). ${ }^{98,99}$ The mesogenic unit is known to stabilize the nematic phase. The transition temperatures of the binaphthyl derivatives upon cooling are presented in Table 2. Compound 8-9

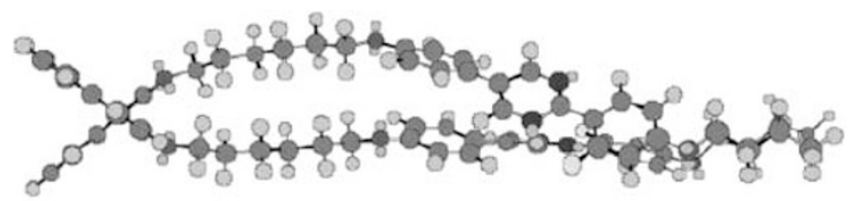

7-6

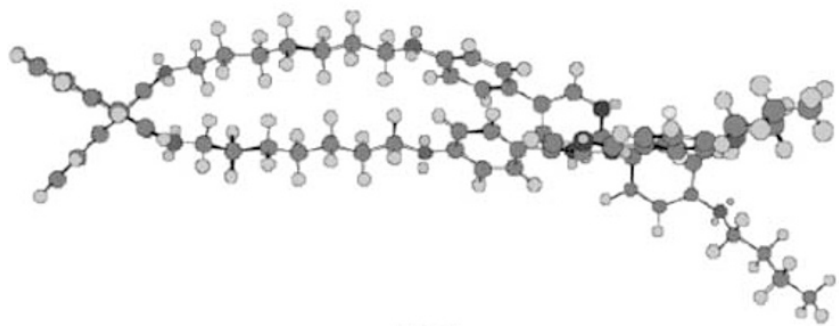

7-7

Figure 13 MM2 models of compounds 7-6 and 7-7.96 (Reprinted with permission from Rokunohe and Yoshizawa, ${ }^{96}$ Copyright 2005, The Royal Society of Chemistry).

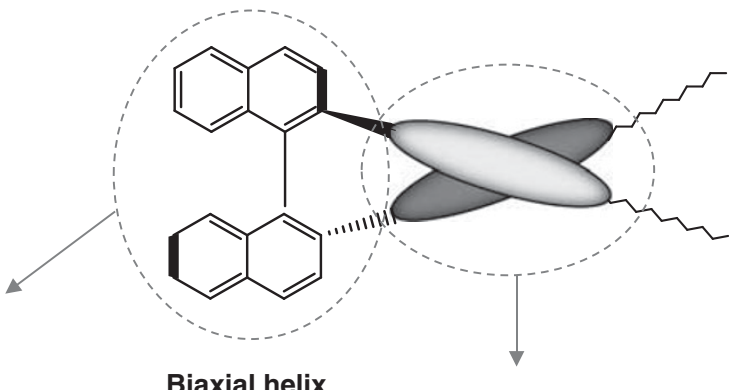

Figure 14 Two origins for the twisting power of the binaphthyl derivatives with odd-numbered spacers. A full color version of this figure is available at Polymer Journal online.

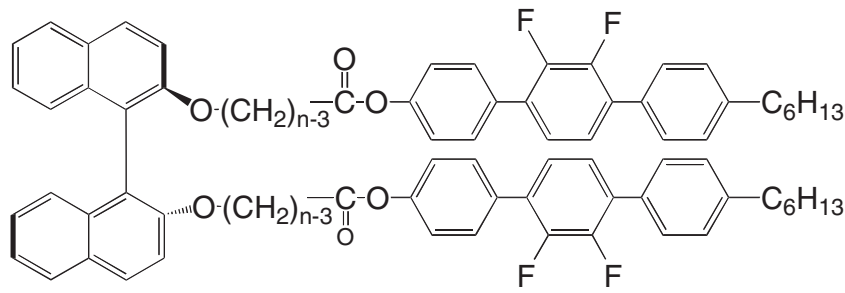

\section{8-n}

Figure 15 Molecular structure of binaphthyl derivative 8-n. 
Table 2 Transition temperatures $\left({ }^{\circ} \mathrm{C}\right)$ of compounds $8-n^{99}$

\begin{tabular}{|c|c|c|c|c|c|c|c|}
\hline$n$ & Cry & glass & $\operatorname{smx}$ & & $N^{*}$ & $B P$ & 1 \\
\hline 8 & - 103 & {$[\bullet 12.4$} & & $\bullet$ & 92.5] & & $\bullet$ \\
\hline 9 & - $102^{\mathrm{a}}$ & {$[\bullet 7.7$} & $\cdot 40.3$ & & & • 71.2] & $\bullet$ \\
\hline 10 & - 86 & {$[\bullet 13.6$} & $\bullet 47.5]$ & $\bullet$ & 87.5 & & $\bullet$ \\
\hline 11 & - 76 & {$[\bullet 7.6$} & $\bullet 67.5]$ & $\bullet$ & 82.2 & & $\bullet$ \\
\hline
\end{tabular}

Square brackets denote a monotropic transition. A bullet means existence of the corresponding phase.

aSome regions in the crystal showed the phase sequence: Cry $68^{\circ} \mathrm{C} \mathrm{N} * 1.5^{\circ} \mathrm{C} \mathrm{BP} 73^{\circ} \mathrm{C}$ Iso on heating, whereas others showed that of $\mathrm{Cry} 102^{\circ} \mathrm{C}$ Iso. This unusual behavior is independent of the position in the sample. Temperatures of the coexistence of crystal and isotropic liquid were about $29 \mathrm{~K} .{ }^{98}$

exhibited a phase sequence of Iso-BP-smectic phase. A platelet texture characteristic of cubic BP was observed. The temperatures of the blue phase with a cubic structure were approximately $30 \mathrm{~K} .{ }^{98}$ The compound exhibits the widest temperature range for a cubic blue phase upon cooling among the reported single compounds. However, unusual hysteresis exists in the phase sequence between the cooling and heating processes. The chiral nematic phase appeared instead of the blue phase upon heating from the smectic phase. ${ }^{98}$ It is noteworthy that the BP mixture reported by Coles and Pivnenko ${ }^{77}$ shows the phase sequence of Iso-BPIII-BPII-BPI-unidentified smectic phase upon cooling. However, upon heating, it shows the phase sequence smectic- $\mathrm{N}^{*}$-Iso. The $\mathrm{N}^{*}$ phase appears only during heating.

No binaphthyl derivative aside from 8-9 exhibited a blue phase. The unusual hysteresis observed for 8-9 was not detected for compounds 8-8, 8-10 and 8-11. The HTP (helical twisting power) of 8- $\boldsymbol{n}$ was calculated using pitch in the mixture of $8-\boldsymbol{n}(2 \mathrm{wt} \%)$ and 4-hexyl-4'-cyanobiphenyl (98 wt\%). The results are as follows: $39.0 \mu \mathrm{m}^{-1}$ for $\mathbf{8 - 8}, 9.9 \mu \mathrm{m}^{-1}$ for $\mathbf{8 - 9}, 27.2 \mu \mathrm{m}^{-1}$ for $\mathbf{8 - 1 0}$ and $2.1 \mu \mathrm{m}^{-1}$ for 8-10.99 A marked odd-even effect was observed for HTP. Compound 8-9 exhibiting BP shows a much smaller HTP value than the other compounds. We next investigated the temperature dependences of chiral nematic helical pitch values induced by each $\mathbf{8 -}$ $n$ with a host nematic liquid crystal: 4-(4-hexylphenyl)-1-(4propyloxyphenyl)-2,3-difluorobenzene. ${ }^{99}$ The host nematic compound possesses the same mesogenic unit as the chiral binaphthyl derivative 8- $\boldsymbol{n}$. A reason for using the compound as a host material is that favorable core-core interactions between a terphenyl moiety of the host LC and each terphenyl moiety of 8- $\boldsymbol{n}$ are expected to occur in the chiral nematic mixture. Helical pitches in the chiral nematic phase of a mixture of $8-\boldsymbol{n}(50 \mathrm{~mol} \%)$ and the nematic LC ( $50 \mathrm{~mol} \%)$ were observed as a function of temperature. The chiral compounds with even-numbered spacers (8-8 and 8-10) were found to induce left-handed helical structures with short pitches. The respective temperature dependences of the induced pitches were small. However, the compounds with odd-numbered spacers (8-9 and 8-11) were found to exhibit temperature-dependent helical twist inversion, which might be induced by competition in the twisting power between the binaphthyl axis and the twisted conformation of the mesogenic cores. Recently, the relation between the appearance of a blue phase and twist inversion in a chiral nematic phase below the blue phase was reported. ${ }^{100}$ The relation supports the effect of the biaxial helix on stabilizing blue phases. The two helical origins of compound 8-9 can produce the biaxial helix to stabilize the doubletwist structures of the blue phase. With respect to compound 8-11, the twisting power is too weak to induce a blue phase.

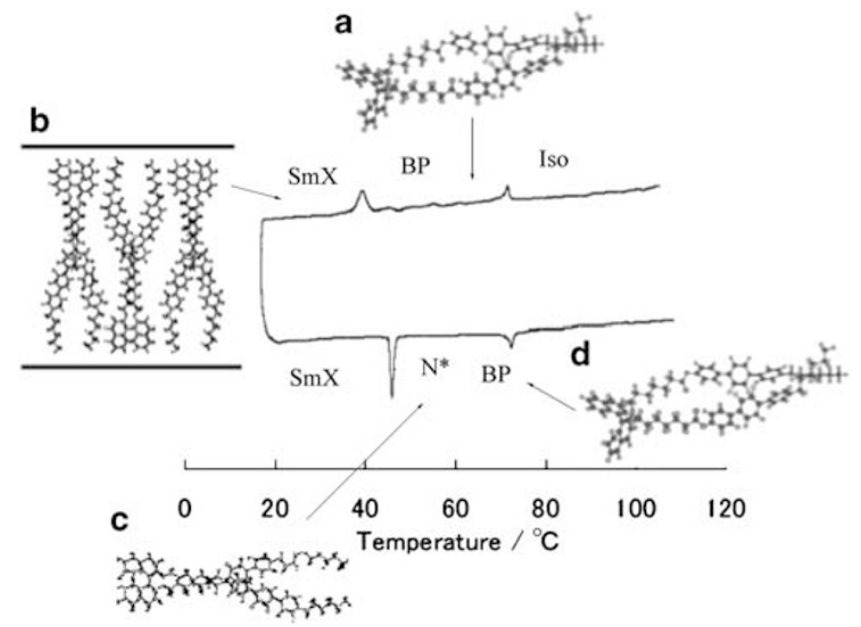

Figure 16 Molecular organization model for the phase behavior of 8-9.99 Conformation of $8-9$ in the BP (a), that in the SmX (b), that in the $\mathrm{N}^{*}$ phase (c) and that in the BP (d). (Reprinted with permission from Kogawa and Yoshizawa, ${ }^{99}$ Copyright 2011, Taylor \& Francis). A full color version of this figure is available at Polymer Journal online.

Figure 16 portrays a molecular organization model for the unusual phase behavior of 8-9. XRD studies of compound 8-9 revealed that the SmX phase has a monolayer structure consisting of cisoid forms. ${ }^{98}$ In the $\mathrm{BP}$, compound $\mathbf{8 - 9}$ is thought to exist as a cisoid form possessing two origins for the twisting power: the binaphthyl axis and the twisted conformation of the mesogenic units (Figure 16a). The cisoid conformers can stabilize the blue phase. Cooling to the SmX phase, the mesogenic units in the cisoid form prefer a parallel alignment because of the favorable packing in each layer structure (Figure 16b). During heating from the SmX phase, compound 8-9 might produce a cisoid form in which the two mesogenic units remain aligned as parallel (Figure 16c). The cisoid conformer does not have two helical origins and cannot induce the biaxial helix. Therefore, the $\mathrm{N}^{\star}$ phase appears instead of the BP phase. During further heating, the two mesogenic cores can form a twisted conformation in the cisoid form (Figure 16d), which produces the $\mathrm{N}^{*}$-to-BP transition.

\section{Chiral T-shaped compounds stabilizing amorphous BPIII}

We designed T-shaped chiral compound 9. ${ }^{101}$ The molecular structure and phase transition temperatures are shown in Figure 17a. Crystal structure of its homolog is shown in Figure 17b. ${ }^{102}$ The blue-colored phase showed fluidity, and it did not appear as platelets, which are usually observed in BPI and BPII, thereby indicating that the blue phase is BPIII. The T-shaped compound exhibited BPIII with a wide temperature range upon cooling. The crystal structure of the T-shaped compound indicates that (1) the compound forms a $\lambda$ shape instead of a T shape and (2) gauche and trans conformations coexist in the central spacer. ${ }^{102}$ On decreasing the optical purity, the Iso-BPIII transition temperature did not change; however, the BPIII$\mathrm{N}^{\star}$ transition temperature increased. ${ }^{102}$ The T-shaped system is thought to have two origins of twisting power: the chiral center and a twisted conformation of the two mesogenic moieties via intramolecular chirality transfer, which can induce the biaxial helix to stabilize the double-twist cylinders (Figure 18).

Then, we introduced a polar group into the chiral T-shaped system to couple the molecule with an electric field. Figure 19 depicts the molecular structures and transition temperatures of the polar chiral compounds. Compound $\mathbf{1 0}$ possesses one terminal cyano group that exhibited BPIII and $\mathrm{N}^{\star}$ phases on cooling. ${ }^{103}$ Electrooptical switching 


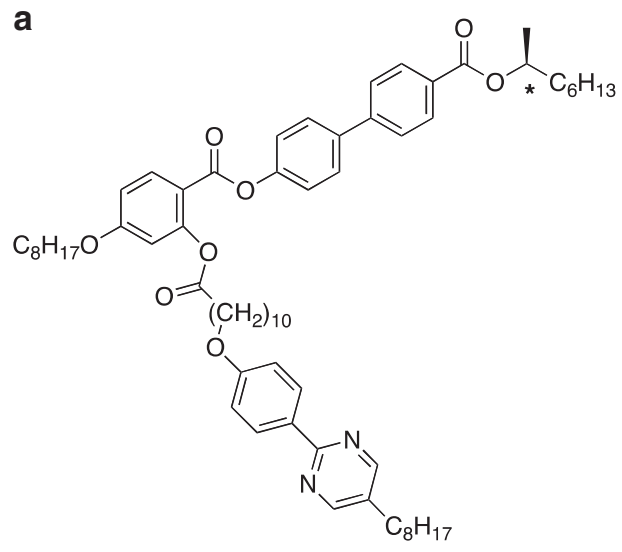

b

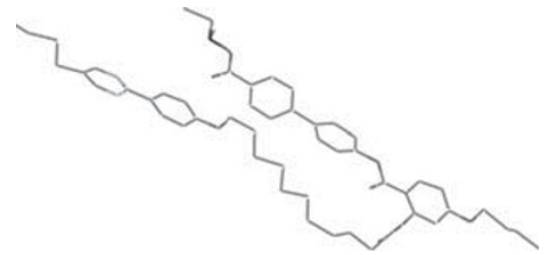

\footnotetext{
9: $\mathrm{Cr} 63^{\circ} \mathrm{C}\left[\mathrm{N}^{\star} 15 \mathrm{BP} 28\right.$ ] Iso
}

Figure 17 (a) Molecular structure with phase transition temperatures of compound $\mathbf{9}$ and (b) the crystal structure for its homolog. A full color version of this figure is available at Polymer Journal online.

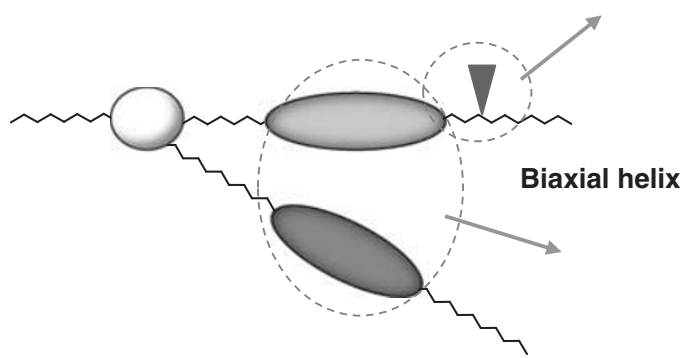

Figure 18 Two origins of twisting power for the T-shaped system. A full color version of this figure is available at Polymer Journal online.

was observed in BPIII. Figure 20a portrays the cell geometry, and Figure $20 \mathrm{~b}$ presents the voltage-transmittance curve at $47^{\circ} \mathrm{C} .{ }^{103,104}$ The dark state with a transmittance of $0.9 \%$ is obtainable in BPIII that is macroscopically isotropic. The change in transmittance as a function of an AC field is attributed to an electric-field-induced

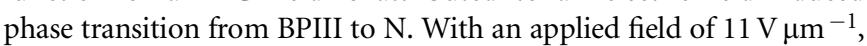
the texture showed a homogeneous bright state with a transmittance of $80 \%$. The rise and decay times with an AC field at $12 \mathrm{~V} \mu \mathrm{m}^{-1}$ at $49^{\circ} \mathrm{C}$ were, respectively, 4 and $6 \mathrm{~ms}$. The rise time is independent of the temperature. However, the decay time lengthens with decreasing temperature. Figure 21 presents a schematic representation of the electric-field-induced phase transition between BPIII and N. Actually, BPIII has a twisted-nematic order that exists microscopically, although it appears to be macroscopically isotropic. The applied electric field amplifies the nanometer-scale order of the twisted organization in the BPIII to the micrometer-scale order of the anisotropic nematic organization, which induces a marked change in the birefringence. However, once the electric field is removed, the molecules form the hierarchical double-twist structure in BPIII.

We introduced a flexible spacer into the T-shaped system to expand the BPIII temperature range. Compound $\mathbf{1 1}$ exhibits BPIII with a temperature range of $25 \mathrm{~K}$, including room temperature upon cooling. ${ }^{105}$ Furthermore, the BPIII changed to a glass phase. Electrooptical switching was observed for almost all temperature ranges of BPIII. However, the response times for both the rise and decay processes lengthened with decreasing temperature. The rise and decay times at room temperature are unexpectedly long. Those times at $22^{\circ} \mathrm{C}$ are 200 and $600 \mathrm{~ms}$, respectively. The response times for the chiral $\mathrm{T}$-shaped system are too long to use for display device applications.

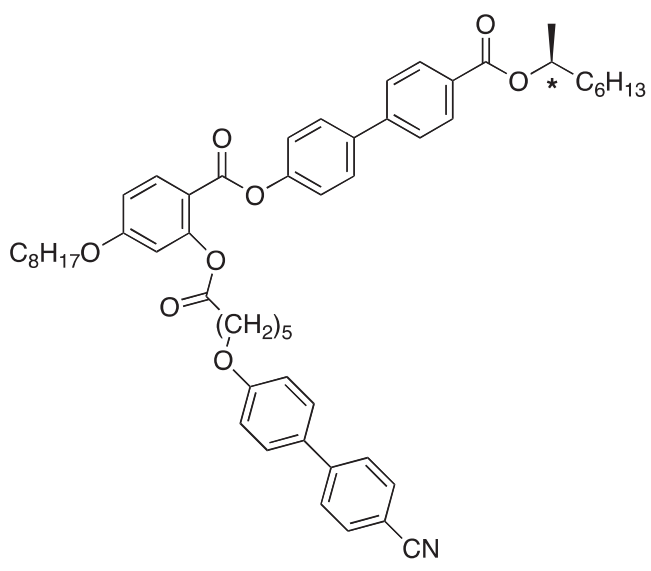

10: Cry $63^{\circ} \mathrm{C}\left[\mathrm{N}^{*} 15^{\circ} \mathrm{C}\right.$ BP $\left.28^{\circ} \mathrm{C}\right]$ Iso

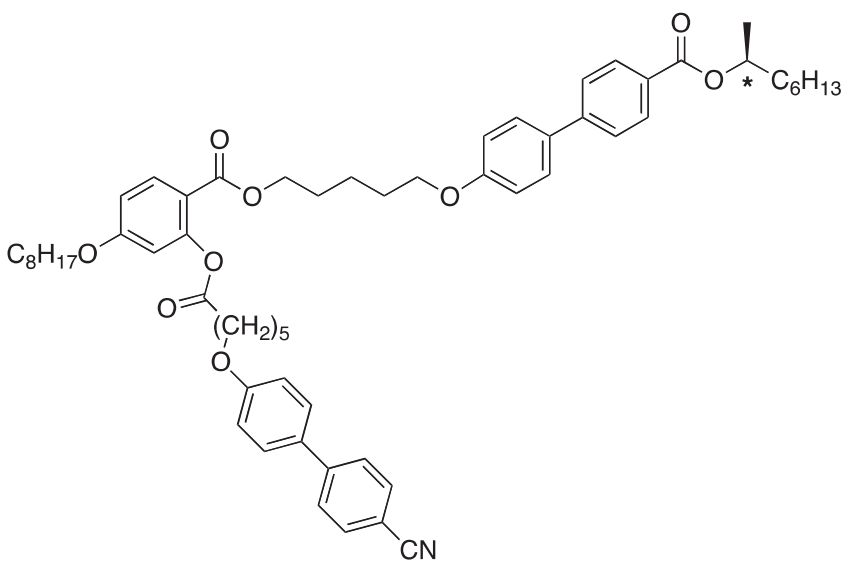

11: Cry $75^{\circ} \mathrm{C}$ [ glass $-8.2^{\circ} \mathrm{C}$ BPIII $24.7^{\circ} \mathrm{C}$ ]lso

Figure 19 Molecular structures and phase transition temperatures of polar T-shaped compounds 10 and $\mathbf{1 1} .^{103,105}$.

\section{Binary system}

We then designed a binary system of a host nematic liquid crystal and a chiral compound. We prepared a nonchiral liquid crystal compound in which a cyano-containing mesogenic moiety and a fluorinecontaining mesogenic moiety are connected via a flexible spacer. ${ }^{106}$ 


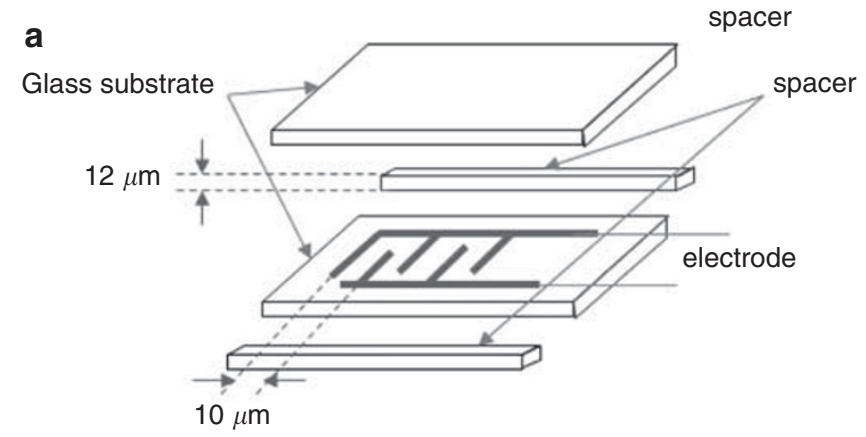

b

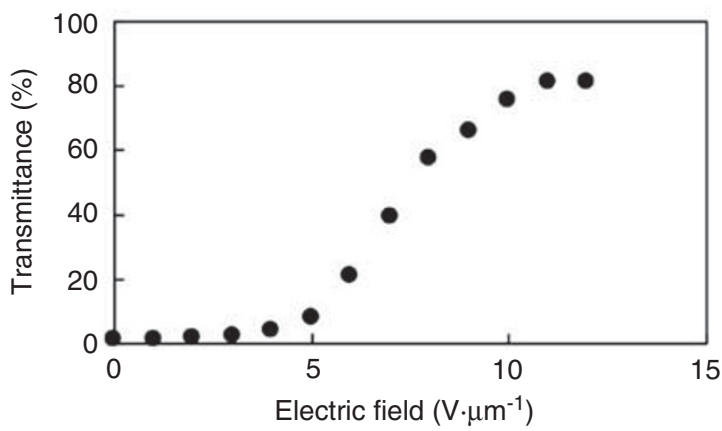

Figure 20 (a) Cell geometry for measurements of the electrooptical effect; (b) optical transmittance as a function of an AC field at a frequency of $10 \mathrm{~Hz}$ at $47^{\circ} \mathrm{C}$. A full color version of this figure is available at Polymer Journal online.

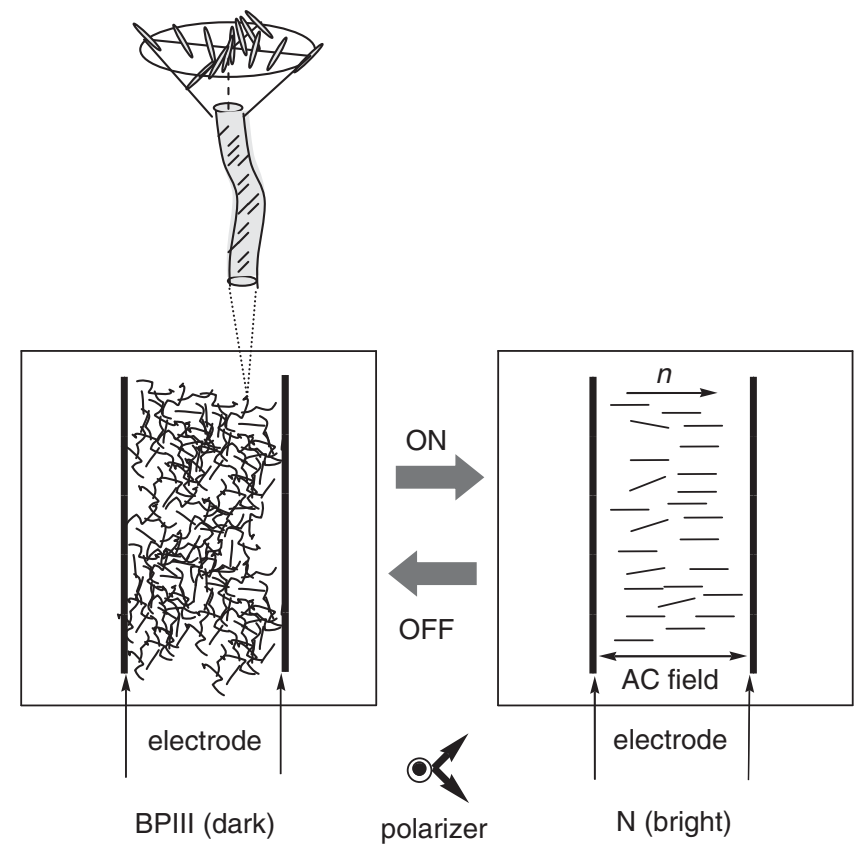

Figure 21 Schematic representation of the electric-field-induced phase transition between BPIII and N. A full color version of this figure is available at Polymer Journal online.

Compound 12 showed an enantiotropic nematic phase. We investigated the phase transition behavior of binary mixtures of compound 12 and a chiral smectic liquid crystal (S811). The molecular structures and transition temperatures of compound $\mathbf{1 2}$ and S811 are shown in Figure 22. For mixtures containing 30-60 wt $\%$ S811, blue phases were induced. In a mixture of S811 (50 wt \%) and compound 12 (50wt\%), the isotropic liquid changed to BPIII at $49.3^{\circ} \mathrm{C}$. The BPIII changed to an $\mathrm{N}^{*}$ phase at $41.2^{\circ} \mathrm{C}$. In a mixture of S811 (40 wt\%) and compound 12 (60 wt\%), a platelet texture characteristic of cubic BP appeared at $70.2^{\circ} \mathrm{C}$; it then changed to a typical chiral nematic texture at $65.1^{\circ} \mathrm{C}$. The fluorine-containing LC compound 12 stabilizes the blue phases. The rise and decay times in

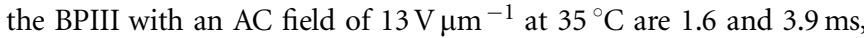
respectively. ${ }^{107}$ The binary system in which the T-shaped structure and chiral portion are separated shows shorter response times than those of the chiral T-shaped system. ${ }^{107}$

We then designed another binary system of biphenyl derivative 13 and chiral additive ISO-(6OBA) ${ }_{2}{ }^{108}$ The molecular structures are shown in Figure 23. The chiral compound, which possesses high twisting power, ${ }^{109}$ is well known to induce blue phases in a mixture with a nematic liquid crystal. ${ }^{68,77,84,87}$ Compound 13 doped with $10 \mathrm{wt} \%$ chiral additive showed phase transition temperatures of Iso 85.4 ${ }^{\circ} \mathrm{C}$ BPIII $70.6^{\circ} \mathrm{C}$ cubic BP $47.3^{\circ} \mathrm{C} \mathrm{N}^{\star} 37.3^{\circ} \mathrm{C}$ unidentified smectic phase. The rise times in both BPIII and cubic BP were approximately $10 \mathrm{~s}$, which is much longer than the T-shaped binary system because of the negative dielectric anisotropy of compound 13. Comparing the voltage-dependent transmittance in the BPIII and the cubic BP of the single mixture, the BPIII shows the following advantages: 1) it is free from hysteresis, 2) it has lower transmittance without an electric field, 3) it has lower threshold and saturated voltages and 4) it has a higher stability against an electric field.

\section{Ternary system for the development of practical materials.}

Compared with conventional nematic liquid crystal displays, BP LCDs presents several advantages, as described above. However, important problems, such as high operating voltages, hysteresis, residual transmittance and stability, remain as areas requiring improvement before BP LCDs can be applied to display devices. In particular, voltage-induced hysteresis affects the accuracy of gray-scale control and should therefore be eliminated. Not only a blue phase with a cubic structure (BPI or BPII) but also an amorphous blue phase (BPIII) reportedly exhibits electrooptical switching. However, amorphous BPIII is thought to have a slower response speed than that of cubic BP because the former has a longer correlation length than the latter. Furthermore, the polymer stabilization is recognized as a prerequisite for BP LCDs.

As discussed above, BPIII with the same symmetry as isotropic liquid has favorable characteristics for application to display devices: it is optically isotropic, hysteresis-free and stable in an electric field. To evaluate the electrooptical switching in BPIII at room temperature, we designed a ternary system consisting of a conventional nematic mixture, a T-shaped BP stabilizer and a chiral dopant with high twisting power. ${ }^{110}$ We prepared a host liquid crystal consisting of nematic liquid-crystalline mixture E7 $(95 \mathrm{~mol} \%)$ and a newly designed T-shaped compound 14 (5 mol\%). The molecular structure of the T-shaped compound is shown in Figure 24. E7 consists of 4-pentyl- $4^{\prime}$-cyanobiphenyl (51 wt $\left.\%\right)$, 4-heptyl- $4^{\prime}$-cyanobiphenyl (25 wt\%), 4-octyloxy-4'-cyanobiphenyl (16 wt\%) and 4-pentyl- $4^{\prime \prime}$-cyanoterphenyl ( $8 \mathrm{wt} \%$ ). The T-shaped compound exhibiting no mesogenic phase can stabilize a blue phase. The Iso- $\mathrm{N}$ transition temperature of the host liquid crystal was $52^{\circ} \mathrm{C}$. The dielectric anisotropy was 12.2 in the $\mathrm{N}$ phase at $25^{\circ} \mathrm{C}$. The host liquid crystal was doped with $15 \mathrm{wt} \%$ of a chiral compound ISO-(6OBA) $)_{2}$. The mixture showed phase transition temperatures of Iso $28.4^{\circ} \mathrm{C}$ BPIII $21.2^{\circ} \mathrm{C} \mathrm{N}^{\star}$ upon cooling.

Figure 25 portrays the electric-field dependence of transmittances for the forward and backward processes in the BPIII at $26^{\circ} \mathrm{C}$. The 

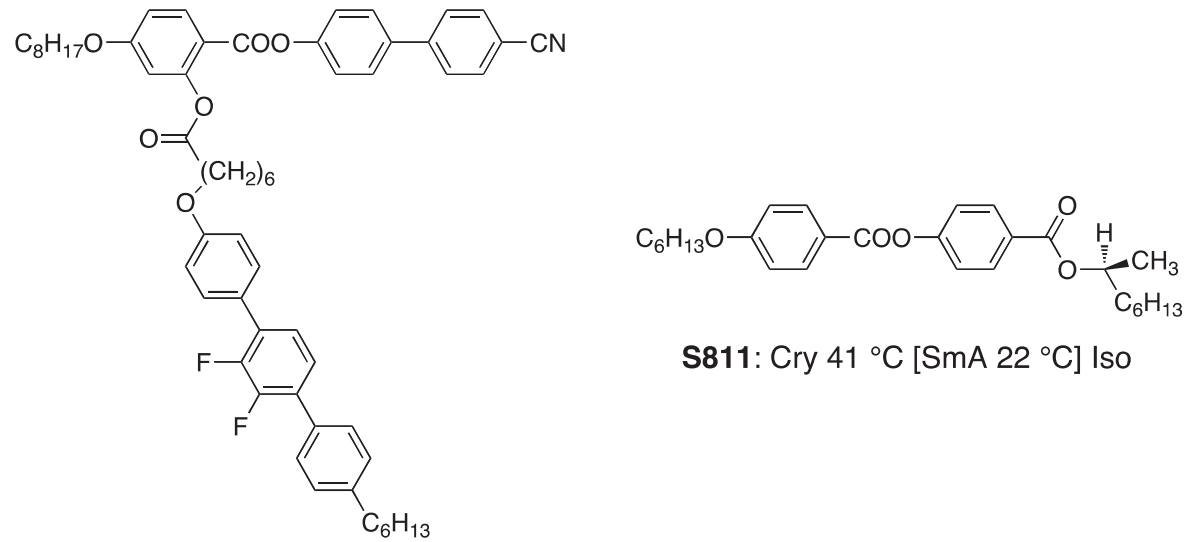

S811: Cry $41^{\circ} \mathrm{C}\left[\mathrm{SmA} 22^{\circ} \mathrm{C}\right]$ Iso

\section{2: Cry $71^{\circ} \mathrm{C} \mathrm{N} 150{ }^{\circ} \mathrm{C}$ Iso}

Figure 22 Molecular structures and transition temperatures of compounds $\mathbf{1 2}$ and $\mathbf{S 8 1 1 . 1 0 6}$

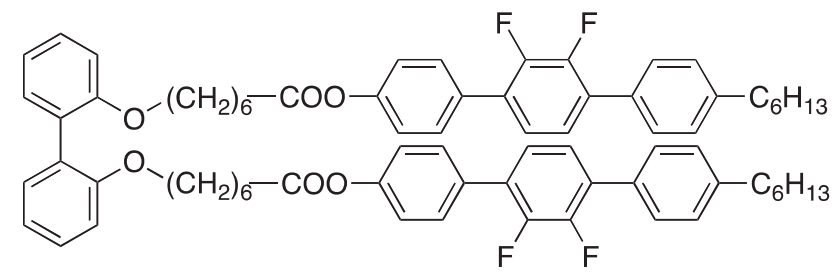

13: Cry $113^{\circ} \mathrm{C}$ [glass $-1.4{ }^{\circ} \mathrm{C}$ SmCanti $69^{\circ} \mathrm{C} \mathrm{N} 106^{\circ} \mathrm{C}$ ] Iso

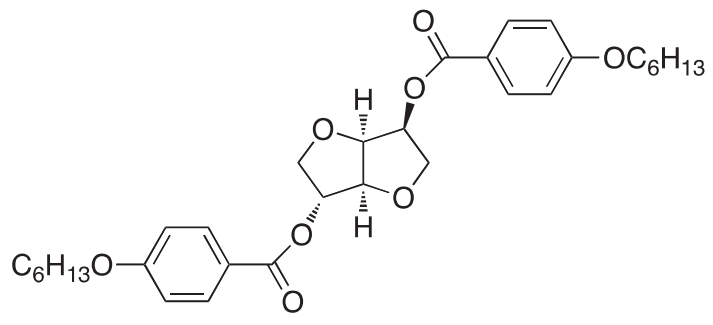

ISO-(6OBA) 2

Figure 23 Molecular structure with phase transition temperatures of binaphthyl derivative 13 and molecular structure of ISO-(6OBA) ${ }_{2}{ }^{108}$

ramping rate was $0.2 \mathrm{~s}$ per step. The cell gap was $5 \mu \mathrm{m}$. The transmittance without an electric field was $0 \%$. The transmittance increased with the increase of the electric field. With an applied field

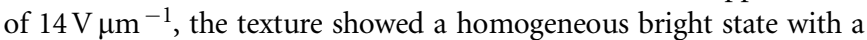
transmittance of $89 \%$, which decreased with the decrease of the electric field. The backward curve was the same as the forward curve. BPIII of the ternary system is free from both hysteresis and residual transmittance. The respective rise and decay times with an AC field of $14 \mathrm{~V} \mu \mathrm{m}^{-1}$ at $50 \mathrm{~Hz}$ were 0.4 and $0.8 \mathrm{~ms}$. Sub-millisecond switching in the BPIII is demonstrated. The decay time depends on the cell gap. The decay time in a cubic BP is independent of the cell gap because the correlation length is much shorter than the distance between the glass substrates. However, with respect to amorphous BPIII, there is no periodicity between defects. It should be noted that the rise time in a blue phase is often affected by the cell gap. Increasing the distance between two glass substrates of the in-plane-switching cell shown in Figure 20a might induce an inhomogeneous electric field in the cell,

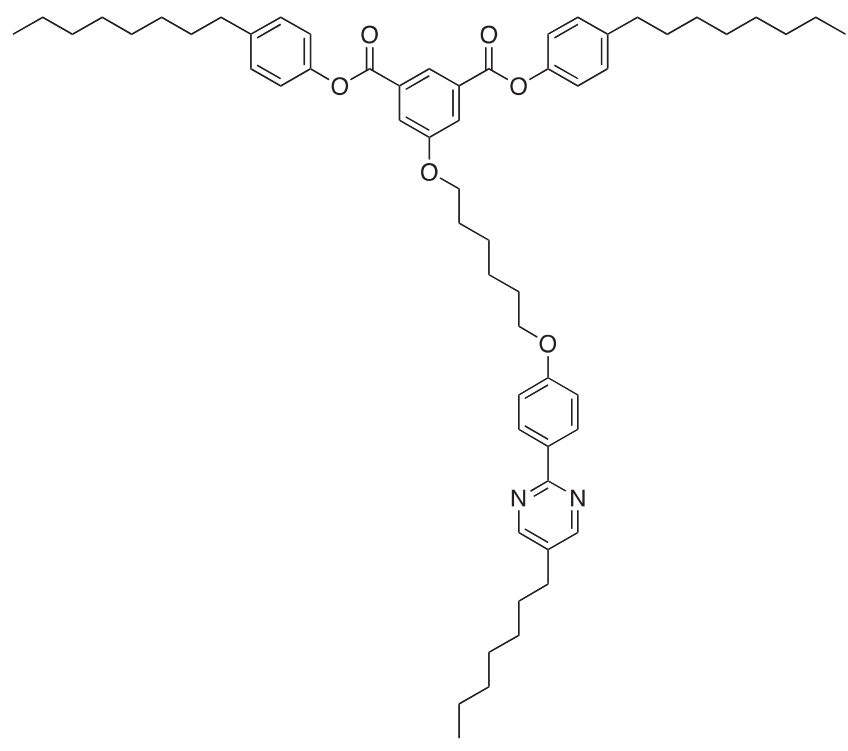

14

Figure 24 Molecular structure of compound 14.

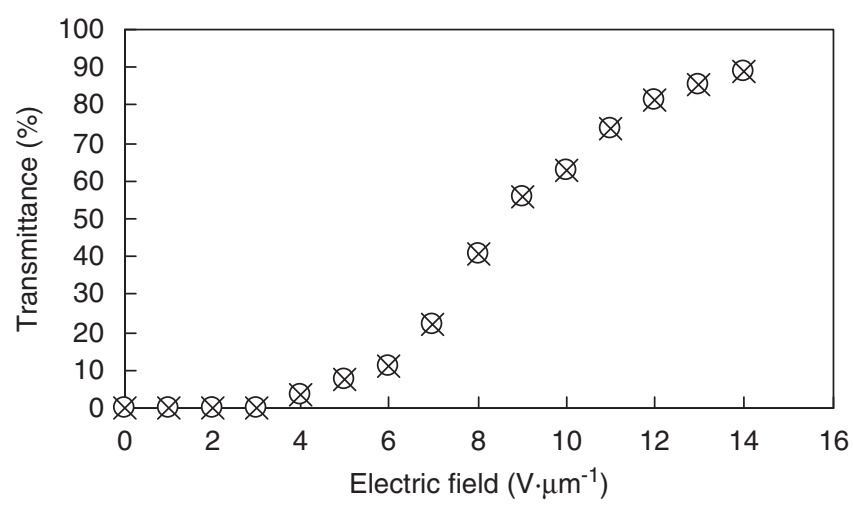

Figure 25 Optical transmittances of the chiral mixture as a function of an AC field at a frequency of $50 \mathrm{~Hz}$ in BPIII at $26^{\circ} \mathrm{C}$. Open circles and crosses denote ascending and descending processes, respectively. 

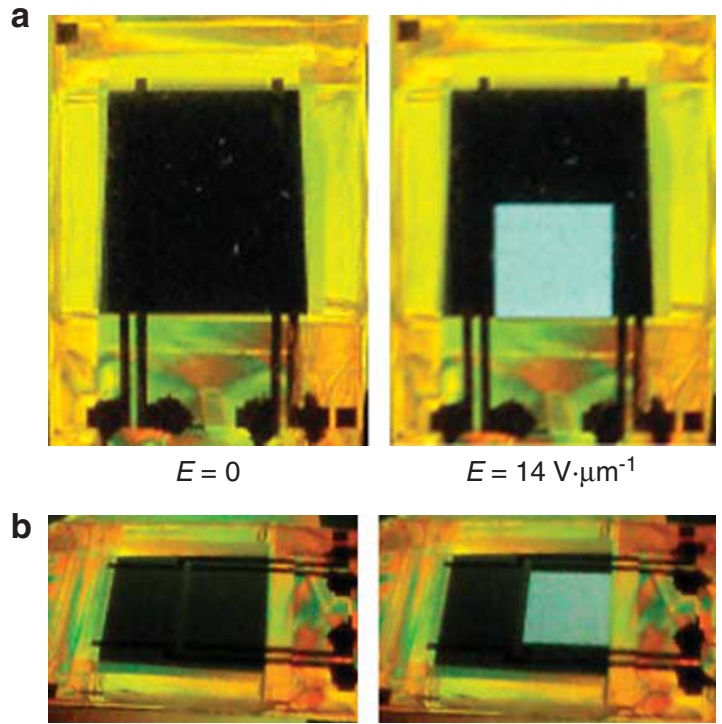

$E=0$

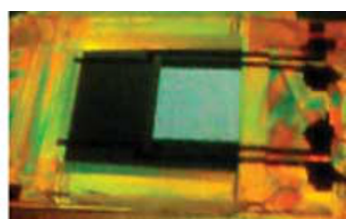

$E=14 \mathrm{~V} \cdot \mu \mathrm{m}^{-1}$

We presented successful approaches to stabilize the blue phases of low-molecular-mass compounds. The binaphthyl derivative showed a cubic BP with a temperature range of $30 \mathrm{~K}$, and the chiral T-shaped compound showed amorphous BPIII with a temperature range of $25 \mathrm{~K}$. Cooperation between the inherent molecular chirality and the chirality-induced twist conformations of the mesogenic units is thought to stabilize double-twist structures in blue phases. Furthermore, we demonstrate the potentiality of BPIII for use in nextgeneration displays.

\section{ACKNOWLEDGEMENTS}

This work was partly supported by a Grant for Hirosaki University Institutional Research, Research for Promoting Technological Seeds (JST), a Grant-in-Aid for Scientific Research (C) from the Japan Society for the Promotion of Science (No. 19550175), a Grant-in-Aid for Scientific Research (B) from the Japan Society for the Promotion of Science (No. 22350078) and a Grant-in-Aid for Scientific Research (No. 23107503) on the Innovative Areas: 'Fusion Materials' (Area no 22006) from MEXT. I particularly thank coworkers who wrote the papers cited in the references.

Figure 26 Viewing-angle dependence of transmittance in the BPIII cell. (a) Front and (b) oblique views with a viewing angle of approximately $45^{\circ} .110$ (Reprinted with permission from Yoshizawa et al. ${ }^{110}$ Copyright 2011, the Japan Society of Applied Physics).

resulting in a slower response. Figure 26 portrays front views (Figure 26a) and oblique views with a viewing angle of approximately $45^{\circ}$ (Figure 26b) of the evaluation BPIII cell sandwiched with crosspolarized films. The BPIII cell has wide viewing angles because of the optical isotropy of BPIII. After the BPIII cell had been preserved for 1 month at $25^{\circ} \mathrm{C}$, the electrooptical switching was confirmed as being identical to that of the virgin state. We also presented a possible design concept by which BPIII materials are obtainable, as follows: (1) develop a basic nematic mixture possessing favorable physical properties, (2) prepare a host LC by adding a small amount of a BP stabilizer to the basic mixture and (3) dope a chiral additive to the host LC. The high driving voltage and the narrow temperature range of the present BPIII LC are expected to be improved through appropriate material design. Amorphous BPIII, with a level of symmetry equal to that of an isotropic liquid, has a superior potential for use in next-generation displays.

\section{CONCLUSION}

We described the molecular design of liquid crystal supermolecules stabilizing cubic and blue phases. A cubic phase in amphiphilic thermotropic liquid crystals is generally recognized as appearing between lamellar and columnar phases by increasing the value of the interface curvature between hydrophilic regions and lipophilic regions. The present amphiphilic-tapered oligomeric system showed an unusual phase sequence of lamellar-columnar-bicontinuous cubic when the number of cyanobiphenyl moieties was increased. The competition of two different molecular packings, that is, (a) a segregation effect attributable to incompatibility between a semiperfluorinated moiety and cyanobiphenyl mesogens and (b) a steric effect attributable to a pronounced taper liquid crystal oligomer, might induce the fluctuating lamellar structure in the SmA phase. The fluctuating structure is most likely stabilized by antiparallel dipoledipole interactions between the cyanobiphenyl groups in adjacent layers. Competition between the oligomeric structure and hydrocarbon/fluorocarbon amphiphilicity can produce fluctuations to induce the lamellar-to-cubic phase transition.

1 Demus, D. Chemical structures and mesogenic properties. in Handbook of Liquid Crystals Vol. 1 (eds Demus, D., Goodby, J. W., Gray, G. W., Spiess, H.-W. \& Vill, V.) 115-187 (Wiley-VCH, Weinheim, 1998).

2 Goodby, J. W. Phase structures of calamitic liquid crystals. in Handbook of Liquid Crystals Vol. 2A (eds Demus, D., Goodby, J. W., Gray, G. W., Spiess, H.-W. \& Vill, V.) 3-20 (Wiley-VCH, Weinheim, 1998).

3 Giroud-Godquin, A. M. Metal-containing liquid crystals. in Handbook of Liquid Crystals Vol. 2B (eds Demus, D., Goodby, J. W., Gray, G. W., Spiess, H.-W. \& Vill, V.) 901-932 (Wiley-VCH, Weinheim, 1998).

4 Bruce, D. W. Metal-containing liquid crystals. in Inorganic Materials. 2nd edn (eds Bruce, D. W. \& O'Hare, D.) 433-462 (John Wiley \& Sons, New York, 1997).

5 Praefcke, K. \& Singer, D. Charge-transfer systems. in Handbook of Liquid Crystals Vol. 2B (eds Demus, D., Goodby, J. W., Gray, G. W., Spiess, H.-W. \& Vill, V.) 945-967 (Wiley-VCH, Weinheim, 1998).

6 Kato, T. Hydrogen-bonded systems. in Handbook of Liquid Crystals Vol. 2B (eds Demus, D., Goodby, J. W., Gray, G. W., Spiess, H.-W. \& Vill, V.) 969-979 (Wiley-VCH, Weinheim, 1998).

7 Goodby, J. W., Mehl, G. H., Saez, I. M., Tuffin, R. P., Mackenzie, G., Auzely-Velty, R., Benvegu, T. \& Plusquellec, D. Liquid crystals with restricted molecular topologies supermolecules and supramolecular assemblies. Chem. Comm. 2057-2070 (1998).

8 Tschierske, C. Micro-segregation molecular shape and molecular topology-partners for the design of liquid crystalline materials with complex mesophase morphologies. J. Mater. Chem. 11, 2647-2671 (2001).

9 Kato, T. Self-assembly of phase-segregates liquid crystal structures. Science 295 2414-2418 (2002).

10 Kato, T., Mizoshita, N. \& Kishimoto, K. Functional liquid-crystalline assemblies: selforganized soft materials. Angew. Chem. Int. Ed. 45, 38-68 (2006).

11 Tschierske, C. Liquid crystal engineering-new complex mesophase structures and their relations to polymer morphologies, nanoscale patterning and crystal engineering. Chem. Soc. Rev. 36, 1930-1970 (2007).

12 Saez, I. \& Goodby, J. W. Supermolecular liquid crystals. J. Mater. Chem. 15, 26-40 (2005).

13 Imrie, C. T. \& Luckhurst, G. W. Liquid crystal dimers and oligomers in Handbook of Liquid Crystals Vol. 2B, (eds Demus, D., Goodby, J. W., Gray, G. W., Spiess, H.-W. \& Vill, V.) 801-833 (Wiley-VCH, Weinheim, 1998).

14 Imrie, C. T. \& Henderson, P. A. Liquid crystal dimers and higher oligomers: between monomers and polymers. Chem. Soc. Rev. 36, 2096-2124 (2007).

15 Imrie, C. T., Henderson, P. A. \& Yeap, G.-Y. Liquid crystal oligomers: going beyond dimers. Liq. Cryst. 36, 755-777 (2009).

16 Donnio, B., Buathong, S., Bury, I. \& Guillon, D. Liquid crystalline dendrimers. Chem Soc. Rev. 36, 1495-1513 (2007).

17 Weissflog, W. \& Demus, D. Liquid-crystalline compound with lateral aromatic branches. Liq. Cryst. 3, 275-284 (1988).

18 Braun, D., Reubold, M., Schneider, L., Wegmann, M. \& Wendorff, J. H. $\lambda$-shaped mesogens: structure, phase formation and properties. Liq. Cryst. 16, 429-443 (1994).

19 Weissflog, W., Demus, D., Diel, S., Nitchke, P. \& Wedler, W. From laterally branched mesogens to novel twin molecules. Liq. Cryst. 5, 111-122 (1989).

20 Andersch, J., Tschierske, C., Diel, S. \& Lose, D. Synthesis and liquid-crystalline properties of novel laterally connected twins: the influence of the connecting topology and the length of the rigid core. J. Mater. Chem. 6, 1297-1307 (1996).

21 Bae, W.-S., Lee, J.-W. \& Jin, J.-I. Comparison of liquid crystalline properties of dimeric compounds of different skeletal shapes. Liq. Cryst. 28, 59-67 (2001) 
22 Goodby, J. W. Twist grain boundary and frustrated liquid crystal phases. Curr. Opin. Colloid Interface Sci. 7, 326-332 (2002).

23 Blatch, A. E., Fletcher, I. D. \& Luckhurst, G. R. Symmetric and non-symmetric liquid crystal dimers with branched terminal alkyl chains: racemic and chiral. J. Mater. Chem. 7, 9-17 (1997).

24 Nishiyama, I., Yamamoto, J., Goodby, J. W. \& Yokoyama, H. A symmetric chiral liquidcrystalline twin exhibiting stable ferrielectric and antiferroelectric phases and a chirality-induced isotropic-isotropic liquid transition. J. Mater. Chem. 11, 26902693 (2001).

25 Yoshizawa, A. Unconventional liquid crystal oligomers with a hierarchical structure. J. Mater. Chem. 18, 2877-2899 (2008).

26 Diel, S. \& Göring, P. Thermotropic cubic phases. in Handbook of Liquid Crystals Vol. 2B (eds Demus, D., Goodby, J. W., Gray, G. W., Spiess, H.-W. \& Vill, V.) 887-900 (Wiley-VCH, Weinheim, 1998).

27 Mariani, P., Vuzzati, V. \& Delacroix, H. Cubic phases of lipid-containing systems: structure analysis and biological implications. J. Mol. Biol. 204 165-189 (1998).

28 Kutsumizu, S. The thermotropic cubic phase: a curious mesophase. Curr. Opin in Solid State \& Mater. Sci. 6, 537-543 (2002).

29 Seddon, J. M. \& Templer, R. H. in Handbook of Biological Physics Vol. 1 (eds Lipowsky, R. \& Sackmann, E.) 97-160 (Elsevier, Amsterdam, 1995).

30 Gulic, A., Delacroix, H., Kirschner, G. \& Juzzati, V. Polymorphism of Gangliosidewater systems: a new class of micellar cubic phases. Freeze-fracture electron microscopy and X-ray scattering studies. J. Phys. // 5, 445-464 (1995).

31 Skoulios, A. E. Mesomorphic properties of block copolymers. In Developments in Block Copolymers Vol. 1 (ed. Goodman, I.) 81-98 (Applied Science Publishers, London, 1982).

32 Antoniette, M. \& Göltner, C. A. Superstructures of functional colloids: chemistry on the nanometer scale. Angew. Chem. Int. Ed. 36, 910-928 (1997)

33 Gray, G. W., Jones, B. \& Marson, F. Mesomorphism and chemical constitution. Part VIII. The effect of 3'-substituents on the mesomorphism of the 4'-n-alkoxydiphenyl-4-carboxylic acids and their alkyl esters. J. Chem. Soc. 393-401 (1957)

34 Diele, S., Brand, P. \& Sackmann, H. X-ray diffraction and polymorphism of smectic liquid crystals. II. D and E modifications. Mol. Cryst. Liq. Cryst. 17, 163-169 (1972).

35 Kutsumizu, S., Yamada, M. \& Yano, S. Mesomorphic phase transitions of a series of D-phase compounds. Liq. Cryst. 16, 1109-1113 (1994).

36 Demus, D., Gloza, A., Hartun, H., Rapthel, I. \& Wiegeleben, A. New thermotropic cubic mesophases. Cryst. Res. Technol. 16, 1445-1451 (1981).

37 Nguyen, H.-T., Destrade, C. \& Malthete, J. Phasmids and polycatenar mesogens. Adv. Mater. 9, 375-388 (1997).

38 Fang, Y., Levelut, A. M. \& Destrade, C. Structural studies of a new series of biforked mesogens derived from 3,4 dialkoxy cinnamic acid and 3-(3,4 dialkoxy-phenyl)propanoic acid. Liq. Cryst. 7, 265-278 (1990).

39 Rowe, K. E. \& Bruce, D. W. The synthesis and mesomorphism of di-, tetra- and hexacatenar liquid crystals based on 2,2'-bipyridine. J. Mater. Chem. 8, 331-341 (1998)

40 Bruce, D. W., Dunmur, D. A., Hudson, S. A., Lalinde, E., Maitlis, P. M., McDonald, M. P., Orr, R., Styring, P., Cherodian, A. S., Richardson, R. M., Feijoo, J. L. \& Ungar, G. Polymorphic ionic mesogens of silver (I): ionic materials exhibiting a thermotropic cubic mesophase. Mol. Cryst. Liq. Cryst. 206, 79-92 (1991).

41 Fazio, D., Mongin, C., Donnino, B., Galerne, Y., Guillon, D. \& Bruce, D. W. Bending and shaping: cubics, calamitics and columnars. J. Mater. Chem. 11, 2852-2863 (2011).

42 Tschierske, C. Molecular self-organization of amphotropic liquid crystals. Prog. Polym. Sci. 21, 775-852 (1996).

43 Borisch, K., Diele, S., Göring, P., Müller, H. \& Tschierske, C. Amphiphilic N-benzoyl1-amino-1-deoxy-D-glucitol derivatives forming thermotropic lamellar, columnar and different types of cubic mesophases. Liq. Cryst. 22, 427-443 (1997).

44 Borisch, K., Tschierske, C., Göring, P. \& Diele, S. Molecular design of thermotropic liquid crystalline polyhydroxy amphiphiles exhibiting columnar and cubic mesophases of the normal type. Chem. Commun. 2711-2712 (1998).

45 Yoshizawa, A., Umezawa, J., Ise, N., Sato, R., Soeda, Y., Kusumoto, T., Sato, T., Hiyama, T., Takanishi, Y. \& Takezoe, H. An unusual endothermic transition to an optically isotropic phase organized by chital molecular recognition. Jpn. J. Appl. Phys. 37, L942-L944 (1998).

46 Takanishi, Y., Ogasawara, Yoshizawa, A., Umezawa, J., Kusumoto, T., Hiyama, T., Ishikawa, K. \& Takezoe, H. Structures in optically isotropic and bluish colored cubic phases formed by enantiomeric association in an $(R, S)$ dichiral compound and a stereoisomeric $(R, R)$ and $(S, S)$ mixture. J. Mater. Chem. 12, 1325-1330 (2002)

47 Kato, T., Matsuoka, T., Nishi, M., Kamikawa, Y., Kanie, K., Nishimura, T., Yashima, E. \& Ujiie, S. Supramolecular chirality of thermotropic liquid-crystalline folic acid derivatives. Angew. Chem. Int. Ed. 43, 1969-1972 (2004).

48 Gustafsson, J., Wahren, H., Almgren, M. \& Larsson, K. Cubic lipid-water phase dispersed into submicron particles. Langmuir 12, 4611-4613 (1996).

49 Fraser, S. J., Rose, R., Hattarki, M. K., Hartley, P. G., Dolezai, O., Dawson, R. M., Separovic, F. \& Polyzos, A. Preparation and biological evaluation on self-assembled cubic phases for the polyvalent inhibition of cholera toxin. Soft Matter 7, 6125-6134 (2011).

50 Yoneya, M., Takada, S., Maeda, Y. \& Yokoyama, H. Electro-optica response of cubic liquid crystal compounds in Kerr cell geometry. Liq. Cryst. 35, 339-342 (2008).
51 Sagara, Y. \& Kato, T. Brightly tricolored mechanochromic luminescence from a singleluminophore liquid crystal: reversible writing and erasing of images. Angew. Chem. Int. Ed. 50, 9128-9132 (2011).

52 Ichikawa, T., Yoshio, M., Hamasaki, A., Kagimoto, J., Ohno, H. \& Kato, T. 3D interconnected ionic nano-channels formed in polymer films: self-organization and polymerization of thermotropic bicontinuous cubic liquid crystals. J. Am. Chem. Soc. 133, 2163-2169 (2011).

53 Suisse, J. M., Mori, H., Monobe, H., Kutsumizu., S. \& Shimizu, Y. Charged carrier mobility in the cubic $(/ a 3 d)$ mesophase of 1,2-bis $\left(4^{\prime}\right.$-n-nonyloxybenzoyl)hydrazine (BABH-9). Soft Matter 7, 11086-11088 (2011).

54 Crooker, P. P.Blue phases. in Chirality in Liquid Crystals (eds Kitzerow, H.-S. \& Bahr,, C.) 186-222 (Springer, New York, 2001)

55 Stegemeyer, H., Blumel, T., Hiltrop, K., Onusseit, H. \& Porsch, F. Thermodynamic, structural and morphological studies on liquid-crystalline blue phases'. Liq. Cryst. 1, 3-28 (1986).

56 Dubois-Violette, E. \& Pansu, B. Frustration and related topology of blue phases. Mol. Cryst. Liq. Cryst. 165, 151-182 (1988).

57 Kitzerow, H.-S. \& Crooker, P. P. Line shapes of field-induced blue phase-III selective reflections. Phys. Rev. Lett. 67, 2151-2154 (1991).

58 Hornreich, R. M. Surface interactions and applied-field effects in cholesteric helicoidal and blue phases. Phys. Rev. Lett. 67, 2155-2158 (1991).

59 Henrich, O., Stratford, K., Cates, M. E. \& Marenduzzo, D. Structure of blue phase III of cholesteric liquid crystals. Phys. Rev. Lett. 106, 107801/1-107801/4 (2011)

60 Cohen, J. The blue phase of cholestric liquid crystals, http://guava.physics.uiuc.edu/ $\sim$ nigel/courses/569/Essays_2002/files/cohen.pdf.

61 Gerber, P. R. Electro-optical effects of a small-pitch blue-phase system. Mol. Cryst. Liq. Cryst. 116, 197-206 (1985).

62 Singh, U. \& Keyes, P. H. Measurement of the Kerr effect in cholesteric blue phases. Liq. Cryst. 8, 851-860 (1990).

63 Porsch, F., Stegemeyer, H. \& Hiltrop, K. Electric field-induced birefringence in liquidcrystalline blue phases. Z. Naturforsch. A. 39a, 475-480 (1984).

64 Heppke, G., Jerome, B., Kitzerow, H.-S. \& Pieranski, P. Electrostriction of the cholesteric blue phases BPI and BPII in mixtures with positive dielectric anisotropy. J. Phys. France 50, 2991-2998 (1991).

65 Stegemeyer, H. \& Porsch, F. Electric field effect on phase transitions in liquidcrystalline blue-phase systems. Phys. Rev. A. 30, 3369-3371 (1984).

66 Gleeson, H. F. \& Coles, H. J. Dynamic properties of blue-phase mixtures. Liq. Cryst. 5, 917-926 (1989).

67 Kitzerow, H.-S. The effect of electric fields on blue phases. Mol. Cryst. Liq. Cryst. 202, 51-83 (1991).

68 Kikuchi, H., Yokota, M., Hisakado, Y., Yang, H. \& Kajiyama, T. Polymer-stabilized liquid crystal blue phases. Nat. Mater. 1, 64-68 (2002).

69 Hisakado, Y., Kikuchi, H., Nagamura, T. \& Kajiyama, T. Large electro-optic Kerr effect in polymer-stabilized liquid-crystalline blue phases. Adv. Mater. 17, 96-98 (2005)

70 Higashiguchi, K., Yasui, K. \& Kikuhci, H. Direct observation of polymer-stabilized blue phase I structure with confocal laser scanning microscope. J. Am. Chem. Soc. $130,6326-6327$ (2008)

71 Rao, L., Ge, Z., Gauza, S., Chen, K.-M. \& Wu, S.-T. Emerging liquid crystal displays based on the Kerr effect. Mol. Cryst. Liq. Cryst. 527, 30-42 (2010).

72 Ge, Z., Wu, S.-T., Kim, S. S., Park, J. W. \& Lee, S. H. Thin cell fringe-field-switching liquid crystal display with a chiral dopant. Appl. Phys. Lett. 92, 181109/1-181109/ 3 (2008)

73 Ge, Z., Rao, L., Gauza, S. \& Wu, S.-T. Modeling of blue phase liquid crystal displays. J. Disp. Technol. 5, 250-256 (2009).

74 Jiao, M., Li, Y. \& Wu, S.-T. Low voltage and high transmittance blue-phase liquid crystal displays with corrugated electrodes. Appl. Phys. Lett. 96, 011102/1-011102/3 (2010).

75 Wang, C.-T., Liu, H.-Y., Cheng, H.-H. \& Lin, T.-H. Bistable effect in the liquid crystal blue phase. Appl. Phys. Lett. 96, 041106/1-041106/3 (2010)

76 Cheng, H.-C., Yan, J., Ishinabe, T. \& Wu, S.-T. Vertical field switching for blue-phase liquid crystal devices. Appl. Phys. Lett. 98, 261102/1-261102/3 (2011)

77 Coles, H. J. \& Pivnenko, M. N. Liquid crystal 'blue phase' with a wide temperature range. Nature 436, 997-1000 (2005).

78 Yelamaggad, C. V., Shashikala, I. S., Liao, G., Rao, D. S. S., Prasad, S. K., Li, Q. \& Jakli, A. Blue phase, smectic fluids, and unprecedented sequences in liquid crystal dimers. Chem. Mater. 18, 6100-6102 (2006).

79 Noma, T., Ojima, M., Asagi, H., Kawahira, Y., Fujii, A., Ozaki, M. \& Kikuchi, H. Effects of polymer network surfaces on expansion of cholesteric blue phases temperature. e-J. Surf. Sci. Nanotechnol. 6, 17-20 (2008).

80 Yoshida, H., Tanaka, Y., Kawamoto, K., Kubo, H., Tsuda, T., Fujii, A., Kuwabata, S., Kikuchi, H. \& Ozaki, M. Nanoparticle-stabilized cholesteric blue phases. Appl. Phys. Express 2, 121501/1-121501/3 (2009).

81 Karatairi, E., Rozic, B., Kutnjak, Z., Tzitzios, V., Nounesis, G., Cordoyiannis, G., Thoen, J., Glorieux, C. \& Kralj, S. Nanoparticle-induced widening of the temperature range of liquid-crystalline blue phases. Phys. Rev. E. 81, 041703/1-041703/5 (2010).

82 He, W., Pan, G., Yang, Z., Zhao, D., Niu, G., Huang, W., Yuan, X., Guo, J., Cao, H., Yang, H. \& H. Wide blue phase range in a hydrogen-bonded self-assembled complex of chiral fluoro-substituted benzoic acid and pyridine derivative. Adv. Mater. 21, 2050-2053 (2009). 
83 Nakata, M., Takanishi, Y., Watanabe, J. \& Takezoe, H. Blue phases induced by doping chiral nematic liquid crystals with nonchiral molecules. Phys. Rev. E. 68, 041710/1041710/6 (2003).

84 Taushanoff, S., Le, K. V., Williams, J., Twieg, R. J., Sadashiva, B. K., Takezoe, H. \& Jakli, A. Stable amorphous blue phase of bent-core nematic liquid crystals doped with a chiral material. J. Mater. Chem. 20, 5893-5898 (2010).

85 Lee, M., Hur, S.-T., Higuchi, H., Song, K., Choi, S.-W. \& Kikuchi, H. Liquid crystalline blue phase I observed for a bent-core molecule and its electro-optical performance. J. Mater. Chem. 20, 5813-5816 (2010).

86 Zheng, Z., Shen, D. \& Huang, P. Wide blue phase range of chiral nematic liquid crysta doped with bent-shaped molecules. New J. Phys. 12, 113018/1-113018/10 (2010).

87 Hur, S.-T., Gim, M.-J., Yoo, H.-J., Choi, S.-W. \& Takezoe, H. Investigation for correlation between elastic constant and thermal stability of liquid crystalline blue phase I. Soft Matter 7, 8800-8803 (2011).

88 Yamaguchi, A., Maeda, Y., Yokoyama, H. \& Yoshizawa, A. Self-assembly of amphiphilic liquid-crystalline oligomers possessing a semiperfluorinated alkyl chain Chem. Mater. 18, 5704-5710 (2006).

89 Yamaguchi, A. \& Yoshizawa, A. Phase transition behaviour of amphiphilic supermolecules possessing a semiperfluorinated alkyl chain. Mol. Cryst. Liq. Cryst. 479 181-189 (2007).

90 Yamaguchi, A. New liquid crystal systems with a hierarchical structure. Ph.D. Thesis, Hirosaki University (2007).

91 Hjduk, D. A., Takenouchi, H., Hillmyer, M. A. \& Bates, F. S. Stability of the perforated layer (PL) phase in diblock copolymer melts. Macromolecules 30, 3788-3795 (1997).

92 Imai, M., Kawaguchi, A., Saeki, A., Nakaya, K., Kato, T., Ito, K. \& Amemiya, Y. Fluctuations of lamellar structure prior to a lamellar-gyroid transition in a nonionic surfactant system. Phys. Rev. E. 62, 6865-6874 (2000).

93 Takeuchi, K., Takanishi, Y., Yamamoto, J. \& Yoshizawa, A. Amphiphilic taper-shaped oligomer exhibiting a monolayer smectic A to columnar phase transition. Liq. Cryst. 37, 507-515 (2010).

94 Yamaguchi, A., Uehara, N., Yamamoto, J. \& Yoshizawa, A. Lamellar to lamellar phase transition driven by conformation change of an amphiphilic liquid crystal oligomer. Chem. Mater. 19, 6445-6550 (2007).

95 Wright, D. C. \& Mermin, N. D. Crystalline liquids: the blue phases. Rev. Mod. Phys. 61, 385-432 (1989).
96 Rokunohe, J. \& Yoshizawa, A. An unusual phase sequence of iso-blue phase-smectic A observed for novel binaphthyl mesogenic derivatives. J. Mater. Chem. 15, 275-279 (2005).

97 Kobayashi, K. \& Yoshizawa, A. Two origins for twisting power of a binaphthyl derivative in a host nematic liquid crystal. Liq. Cryst. 34, 1445-1462 (2007).

98 Yoshizawa, A., Kogawa, Y., Kobayashi, K., Takanishi, Y. \& Yamamoto, J. A binaphthyl derivative with a wide temperature range of a blue phase. J. Mater. Chem. 19, 5759-5762 (2009).

99 Kogawa, Y. \& Yoshizawa, A. Chiral effects of blue phase stabilization of a binaphthyl derivative. Liq. Cryst. 38, 303-307 (2011).

100 Alexander, G. P. \& Yeomans, J. M. Stabilizing the blue phases. Phys. Rev. E. 74, 061706/1-061706/9 (2006).

101 Yoshizawa, A., Sato, M. \& Rokunohe, J. A blue phase observed for a nove chiral compound possessing molecular biaxiality. J. Mater. Chem. 15, 3285-3290 (2005).

102 Sato, M., Ogasawara, F. \& Yoshizawa, A. Novel T-shaped chiral oligomers with a wide temperature range of a blue phase. Mol. Cryst. Liq. Cryst. 475, 99-112 (2007).

103 Sato, M. \& Yoshizawa, A. Electro-optical switching in a blue phase III exhibited by a novel chiral liquid crystal oligomer. Adv. Mater. 19, 4145-4148 (2007).

104 Iwamochi, H. Effects of molecular biaxiality on physical properties of blue phase materials. Master Thesis, Hirosaki University (2009).

105 Iwamochi, H., Hirose, T., Kogawa, Y. \& Yoshizawa, A. Chiral T-shaped semiflexible compound exhibiting a wide temperature range blue phase III. Chem. Lett. 39, 170-171 (2010).

106 Yoshizawa, A., Iwamochi, H., Segawa, S. \& Sato, M. The role of a liquid crysta oligomer in stabilizing blue phases. Liq. Cryst. 34, 1039-1044 (2007).

107 Iwamochi, H. \& Yoshizawa, A. Electro-optical switching in blue phases induced by a binary system of a T-shaped nematic liquid crystal and a chiral compound. Appl. Phys. Express 1, 111801/1-111801/3 (2008).

108 Kogawa, Y., Hirose, T. \& Yoshizawa, A. Biphenyl derivative stabilizing blue phases. J. Mater. Chem. 21, 19132-19137 (2011).

109 Parry, O., Nolan, P., Farrand, L. \& May, A. L. Chiral dopants. W09800428 (1998).

110 Yoshizawa, A., Kamiyama, M. \& Hirose, T. Amorphous blue phase III exhibiting submillisecond response and hysteresis-free switching at room temperature. Appl. Phys. Express 4, 101701/1-101701/3 (2011). 